\title{
Mixed reality-based user interface for quality control inspection of car body surfaces
}

\author{
Adolfo Muñoz, Xavier Mahiques, J. Ernesto Solanes*, Ana Martí, \\ Luis Gracia, Josep Tornero \\ Instituto de Diseño y Fabricación, Universitat Politècnica de València, Camino de Vera \\ s/n, 46022 València, Spain (*Corresponding author e-mail: esolanes@idf.upv.es)
}

\begin{abstract}
In recent years, the quality control of car body surfaces production lines have been put in the context of Industry 4.0. The emergence of automatic defect detection systems have helped to standardize the brand quality and gather information about all quality control tasks performed by workers. However, current worker interfaces used to indicate the location and other characteristics of the defects found by these systems have overcome the ergonomics of workers and increased their stress at work. This paper presents a novel mixed reality-based user interface for quality control inspection which is more intuitive, in order to improve the ergonomics of workers, reduce their stress at work and improve the productivity of current quality control production lines. An experimental prototype is shown in the paper in order to demonstrate the benefits of the proposed interface. In addition, the paper shows the results of several usability tests that compare the proposed mixed realitybased user interface with current interfaces used in important factories such as Mercedes-Benz, analyzing the benefits and drawbacks of each interface.
\end{abstract}

Keywords: Car body surface quality control, mixed reality, augmented reality.

\section{Introduction}

\subsection{Motivation}

Quality control of car body surfaces is one of the most important processes along the production of a car, and yet the process less automated due to the difficulty of meeting the quality standards and cycle times of current 
production lines. There are several occasions in which a car body is put under the eyes of quality control expert workers seeking defects or deformities, e.g. raw plate stage, after the painting process, final finishing [1]. However, it is after the painting process when manufacturing managers introduce a more exhaustive quality control of the car body surface in order to meet with the client requirements. At this stage, possible surface defects can be repaired without incurring in many extra costs.

In most of current factories, quality control after the painting process is still being carried out manually as follows: a group of expert workers check the entire surface of the body seeking defects ranging from $0.2 \mathrm{~mm}$ of diameter to bigger sizes. Once a defect has been located it is marked directly on the surface using a chalk, and following the worker proceeds to repair the defect when possible. In addition, the worker is also in charge of introducing manually throughout PADs (i.e., tablet computers or electronic tablets) the main characteristics of the defect, such as its typology, size and number of times that has been repaired, among others. Some examples of the kind of defects faced by these expert workers can be seen in $[2,3]$.

\subsection{Related work}

From 2008, quality control systems of car body surfaces appear, allowing the automatic detection and location of defects (see Fig. 1). For instance, one of the authors of this work proposed in $[1,4]$ a vision-based quality control system based on the ideas in [5]. This system was composed of a moving structure made up of several fluorescent tubes at high-frequency and a set of cameras in fixed positions around the stationary car body. The authors claimed that this system was able to detect defects of up to $1 \mathrm{~mm}$ in diameter, standardizing and improving the process of quality control of car body surfaces. The system can be found in most of Ford factories in USA and Spain. Unfortunately, this system could only carry out the detection on flat surfaces and those with smooth slope changes, meaning that areas close to all style lines, edges and corners were excluded, reducing considerably the inspection area. In [6], a very similar system installed in the Opel factory, in Spain, was presented, which the main difference was that the inspection was carried out while the car body was moving. Regrettably, information about the algorithm, as well as its performance, is limited. Other commercial systems dealing with defect detection on painted car bodies use robots to cover the entire area, such as in $[2,7]$, installed in Mercedes factories. This approach tried to cover as much area as possible by bringing the vision and 


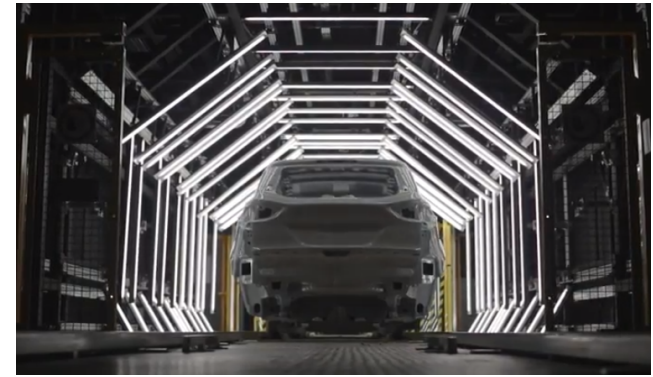

(a) AIS system developed in Ford factories (video $[8]$ ).

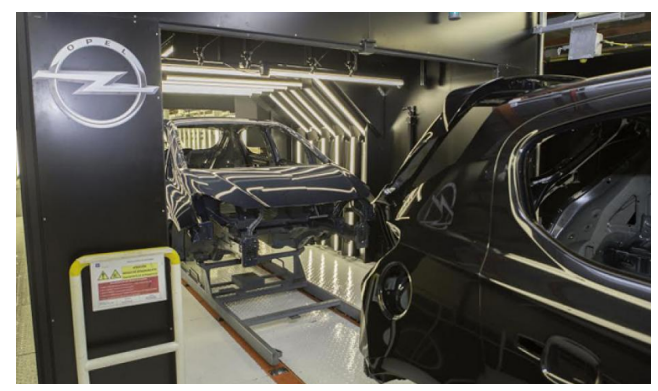

(c) 3DJ Vision system developed in Opel factories (video [10]).

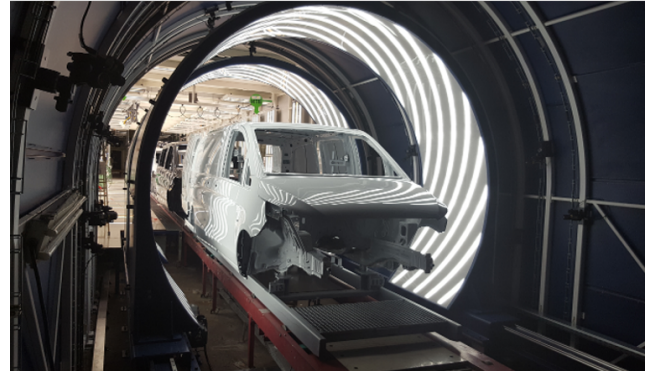

(b) QEyeTunnel system developed in Mercedes factories (video [9]).

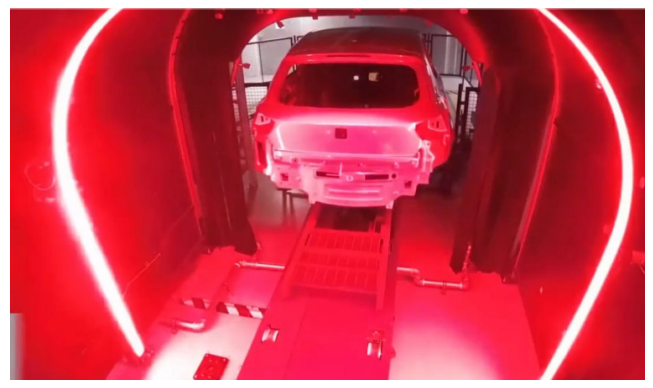

(d) esPhi system developed in Seat factories (video [11]).

Fig. 1. Examples of automatic defect detection systems.

illumination systems close to the body surface. As in the case of [6], no further details about the algorithms are published. However, this system can cover much more area than the system in $[1,4]$ but the time required to perform the inspection is much longer. A more recent system similar to [4] has been developed by several authors of this work in Mercedes-Benz and Volkswagen factories in Spain [3]. This system replaces the fluorescent tubes at high-frequency by LED panels, which allow modifying the shape, size and intensity of the light projected on the surface. The authors claimed that the system was able to detect defects of up to $0.2 \mathrm{~mm}$ in diameter, and not only defects produced by dirt such in the case of $[1,4]$ but also other typologies such as dings and dents. Additionally, this system is able to detect defects in all areas close to style lines, edges and corners as long as the area is well illuminated. 


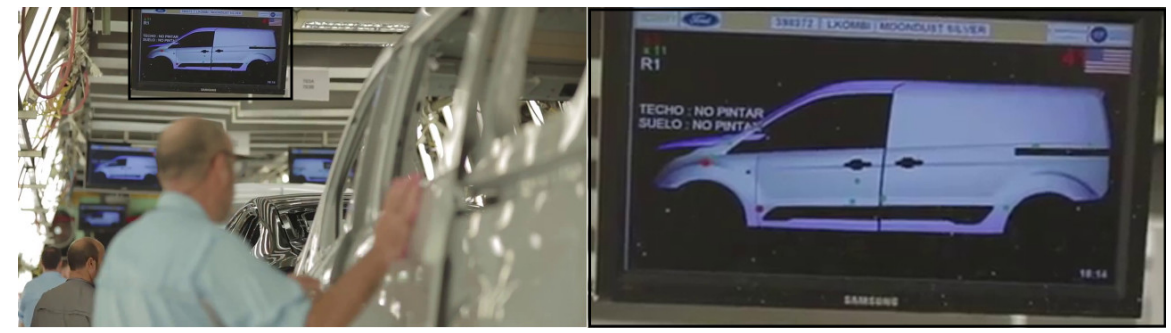

(a) AIS worker interface installed in Ford factories, see the following (video [12]) for more details.

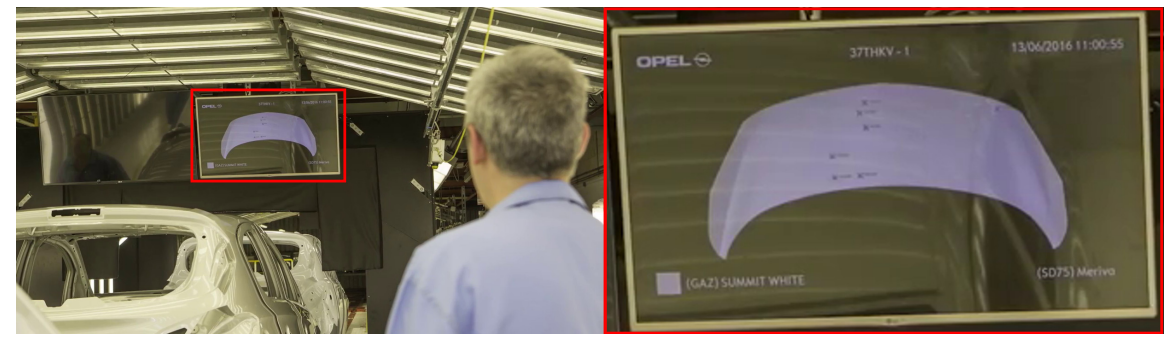

(b) 3DJ Vision worker interface installed in Opel factories, see the following (video [13]) for more details.

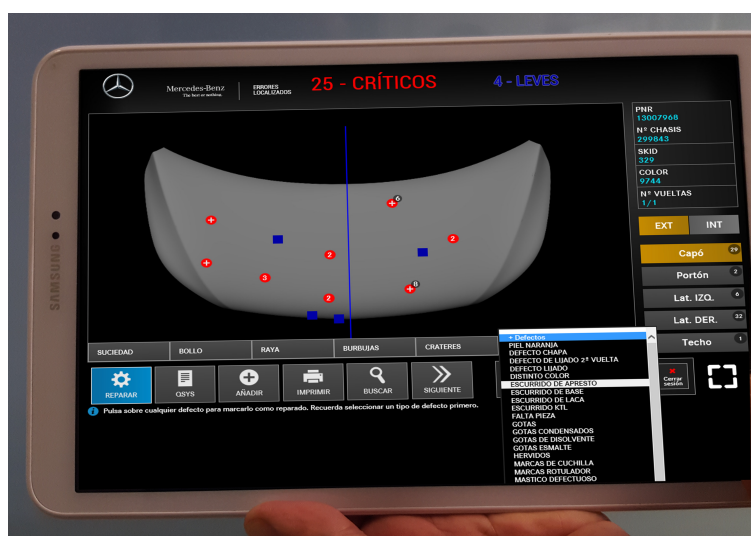

(c) QEyeTunnel worker interface PAD-based installed in Mercedes-Benz factory.

Fig. 2. Examples of worker interfaces developed by different automatic detection systems. 


\subsection{Current issue}

In most factories, workers receive the information from the automatic defect detection systems by means of screens located along the quality control line (see Fig. 2(a) and Fig. 2(b)) or through PADs (see Fig. 2(c)). As shown in Fig. 2, the information received by the workers is $2 \mathrm{D}$ only, and the location of the defects is not very accurate, especially in flat areas where there are no references such as style lines, edges or corners (e.g., in the middle of the hood or door). Thus, the workers have not noticed a relevant benefit in terms of task reduction and ergonomics. In fact, the worker tasks have been increased since they must inform about the performance of the system (i.e., introduction of the information about false positives, non-detections, etc.). Moreover, the worker ergonomics has worsened since they still must inspect large areas looking for the indicated defects in order to confirm them and, in addition, having to carry out PADs. Therefore, there is a need to improve the way of providing the information about the defects location so that the workers can coexist in a more natural and productive way with the automatic defect detection systems, which is the aim of this work.

\subsection{Objective}

In order to improve both ergonomics and productivity of workers involved in the quality control inspection process of car body surfaces, this work introduces a new interface based on Mixed Reality (MR) tools. The proposed MR-based user interface substitutes current 2D devices, i.e., screens, printers, PADs, etc., and provides a more intuitive manner of interacting with current automatic quality control systems and factory servers. The paper provides details of the industrial user interface designed accordingly to the specifications given by automotive managers from important brands such as Mercedes-Benz and Volkswagen. The proposed MR-based user interface is validated using a prototype of automatic defect detection system, a Volkswagen car body together with the Microsoft ${ }^{\circledR}$ HoloLens glasses as MR device. In addition, the paper presents the results of the usability test performed by different users to compare current interfaces based on PADs and the proposed MR-based user interface.

The paper is organized as follows: next section introduces some MR background and a description of the target application. Subsequently, Section 3 presents a full description of the proposed MR-based user interface for quality control of car body surfaces. The effectiveness of the proposed approach 


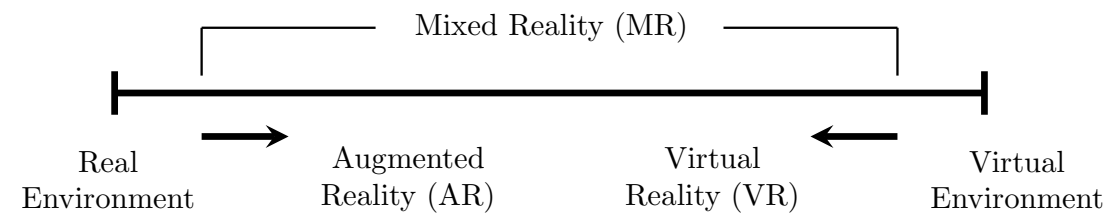

Fig. 3. Simplified representation of Reality-Virtuality Continuum described in [14].

is substantiated by experimental results in Section 4, while Section 5 discusses some details of the study and further considerations. Finally, some conclusions are given in Section 6.

\section{Materials and methods}

\subsection{Mixed reality background}

The current emergence of new concepts, tools and technologies of virtual reality (VR), augmented reality $(\mathrm{AR})$ and mixed reality (MR) [15] open a new scenario for the ergonomic and economic improvement of many current industrial processes. Fig. 3 shows the simplified representation of the Reality-Virtuality Continuum described in [14], which locates the MR in the intermediate space between reality and virtuality. This has started to be considered by most industrial manufacturers, especially to improve their maintenance services in order to guarantee that companies implement efficient production systems $[16,17,18,19]$. However, these technologies are rapidly expanding to other types of industrial processes [20, 21, 22, 23, 24, 25, 26]. As described in [24], most of the industrial applications incorporating MR tools are related with design, maintenance and assembly tasks $(14.52 \%$ of the total), whilst quality control applications using MR are $1.71 \%$ of the total, which indicates also the interest of industrial managers. Despite of this, to the best of the authors' knowledge, this is the first work proposing a MR-based solution for quality control tasks in the automotive industry.

\subsection{Target application}

Without loss of generality, this paper is focused on the quality control of car body surfaces located just after finishing the painting phase of the car body. Fig. 4 shows the block diagram describing the process of quality control in most of current factories in which an automatic defect detection system is being used $[1,2,7,6,3]$. In summary, the car body goes through a 


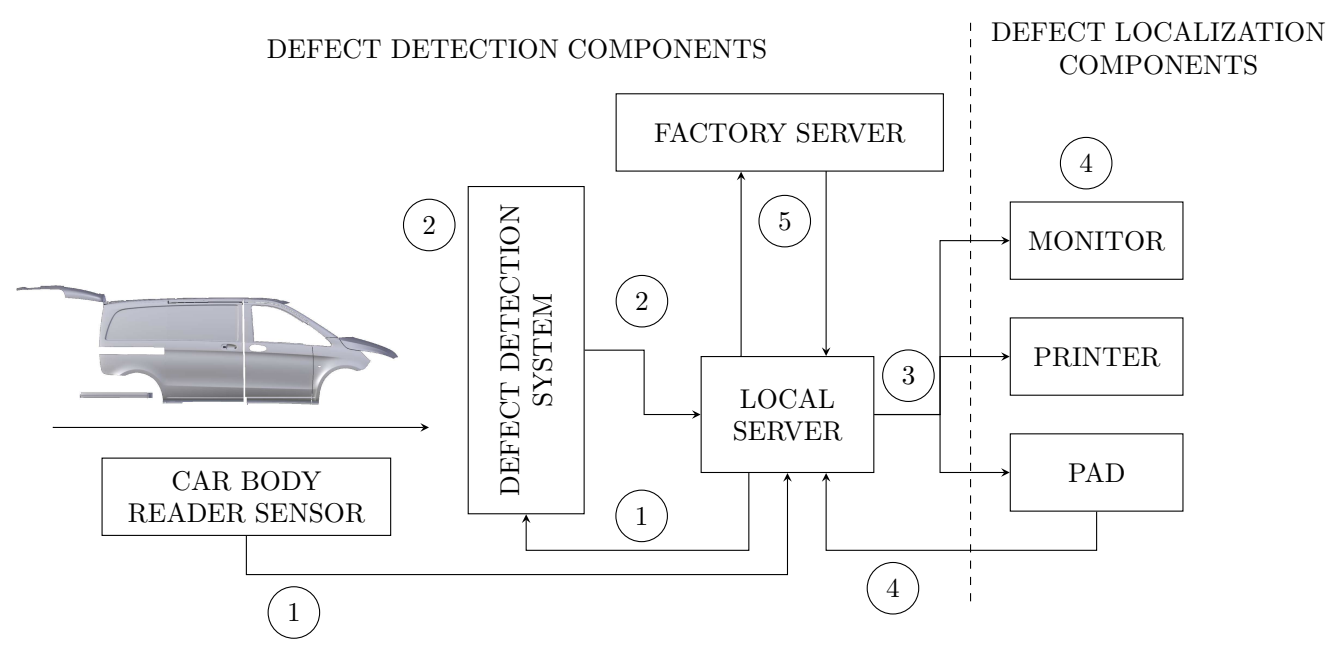

Fig. 4. Quality inspection of car body surfaces block diagram: step 1, the car body is identified and all data needed to carry out the defect detection is uploaded to the system from the local server; step 2, the defect detection system performs the inspection and sends the results to the local server; step 3, results are sent to all devices available to help workers to locate and identify the detected defects on the car body; step 4, the workers can inform about the defect status and modify the local server database; step 5, the local server and the factory server are in communication to upload, save the results, upgrade or save algorithm versions, etc.

detection system that obtains information about the location of the defects and, possibly, other characteristics such as their typology or size. Although other approaches can be found in the literature [27, 28, 29,30,31], current industrial solutions are based on the "deflectometry" principle [32,3] and vision techniques $[1,2,7,6,3]$. The information is then sent by the defect detection system to a local server and stored in its database. When required, the local server sends the information to factory displays such as monitors, printers, PADs, etc. in order to allow the worker to see the information about the inspection.

The worker interface and the manner of showing the information depends on the specifications of each factory. Without loss of generality, in the following, the main characteristics of current interfaces used in Mercedes-Benz factory in Vitoria and Volkswagen in Pamplona, both from Spain (see Fig. 2(c)), are described:

- Credentials: maintenance worker with full access; line worker with restricted access. 
- Visualization of the body on 2D screens: the body is divided into several separate views, i.e., the hood, sides, rear doors, etc.

- Out-of-standard defects are shown in red while defects within standard are shown in blue.

- The interface in PAD allows introducing characteristics of defects such as typology, size, whether it has been repaired or not, the number of times it has been repaired, among others.

- The interface in PAD allows the worker to enter defects that have not been detected automatically.

- The interface in a PAD allows the worker to catalog defects such as False Positive, i.e., defects that the system has indicated but do not exist.

Finally, the local server is also in charge to update the factory servers with all the information required to be stored and subsequently treated.

\section{Theory and development}

In this section the proposed MR-based user interface for quality control inspection of car body surfaces is fully described. Fig. 5 summarizes the steps followed to design, develop, implement and evaluate the proposed MRbased user interface. First, a study about the application requirements was conducted based on interviews with managers of the production line and expert workers. The requirements obtained from this study are described in Table 1.

With this information, a mockup design was realized. From a functionality point of view, the proposed MR application has two types of virtual objects: the first one corresponds to the virtual objects that represent the location of the defects on the car body and the handlers to manually rotate or move the objects on the space; and the second one corresponds to the information panels that interact with the workers. Different mockup design tools and strategies were used to design both types of virtual objects. On the one hand, at first, the virtual objects representing the defect location were modeled in a standard 3D creation suite, concretely in Blender 2.7 [34], and assembled in a virtual space using Unity [35] in a PC workstation. During this design phase, the main virtual object characteristics (i.e., shape, color, 


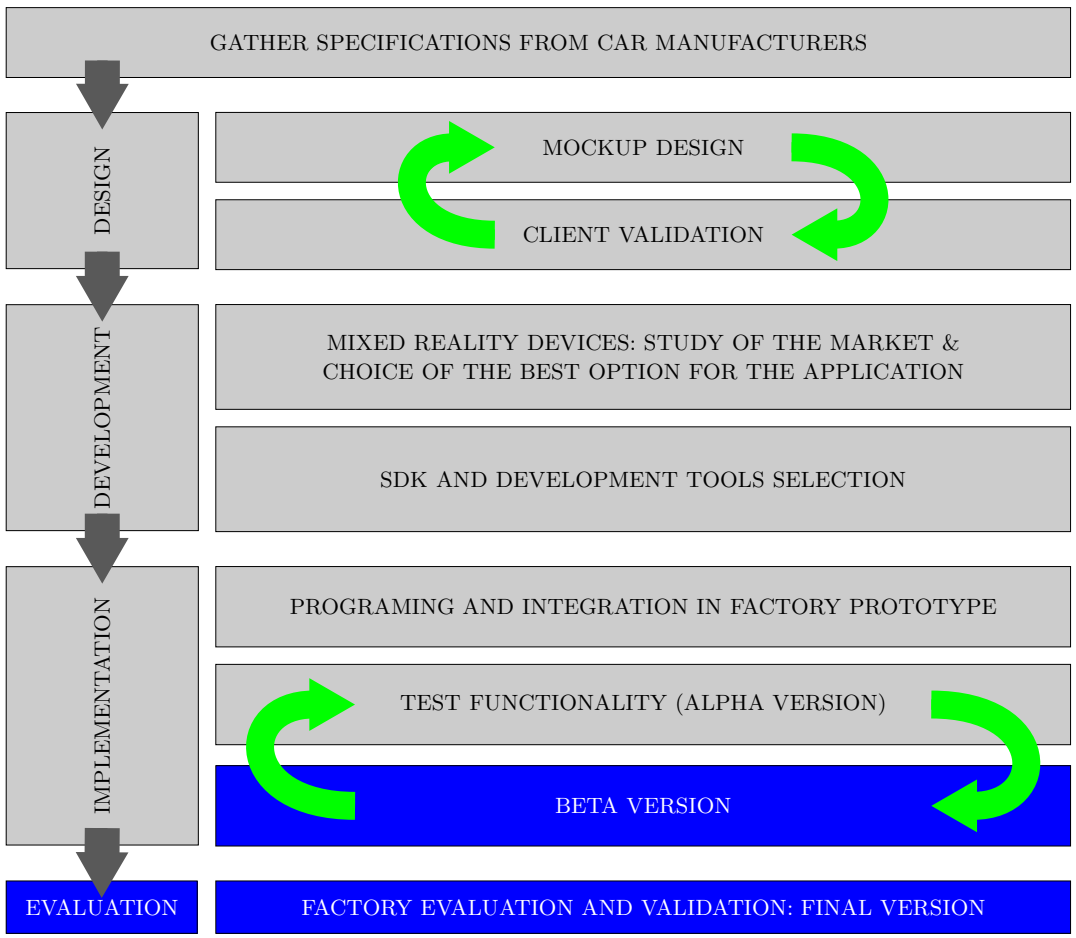

Fig. 5. Methodology followed to design and develop the MR-based user interface for quality control inspection tasks.

size, etc.) and basic interactions ("AirTap") were constantly checked and remade by connecting the $\mathrm{PC}$ with the Microsoft ${ }^{\circledR}$ HoloLens glasses in a remote mode from the Unity editor. On the other hand, the information panels (main panel, defect information panel, etc.) were designed using the tool called Moqups [36], which is widely used to create sketches of web sites. This tool has the advantage that the designed sketches can be shared with the client, who can modify them without programming a line of code (e.g., change the position of the objects within the interface, add comments, add new functionalities, etc.). In this way, the client easily checked the designed sketches and their functionalities and helped to modify them until his compliance with them.

The first MR prototype was completed by integrating both types of objects and the logic to implement the required functions in Unity. Subsequently, the MR application was compiled with Microsoft Visual Studio and 
Table 1. Application requirements.

Free workers from having to carry devices with their hands

The interaction with the new interface should be similar to current operating systems (e.g., Windows 10) so that it will be familiar to the workers

The defect location should be indicated directly on the car body

The worker should have the option to manually introduce new defects not detected by the system

The worker should have the option to define as false positive a defect that has been detected by the automatic defect detection system but that does not exist

The defect representation must clearly distinguish between serious defects, mild defects, false positives and defects not detected (see [33])

A virtual panel must be always visible and report all relevant data of the car body being inspected

The virtual objects must be automatically hidden when the worker approaches to the surface in order to inspect the defect

The worker should have the option to check all the data of a specific defect, i.e., typology, size, status, etc.

The worker should have the option to modify the data of a specific defect.

Two operation modes are required: automatic mode, in which the production line system automatically provides the car body identification number; and manual mode, in which the worker manually introduces the car body identification number. This number will be used by the application to load the car body data from the local server.

Different access modes to the application are required depending on the worker credentials. At least two access modes are needed: full access, for maintenance worker; and restricted access, for the rest of the workers of the production line.

The communications between the application and the factory systems must use existing protocols and standards (e.g., Daimler standard in Mercedes plants)

The communications of the application must be secure and robust

installed in the Microsoft ${ }^{\circledR}$ HoloLens glasses so that the client could test, first in the facilities of the R\&D group (alpha version) and next in the factory (beta version), giving rise to new adjustments until the client's demands were fulfilled ${ }^{1}$.

After the design process, the main functionalities of the MR-based user interface have been established in Table 2. In accordance with these specifications, two main modules are proposed, as shows the block diagram in

\footnotetext{
${ }^{1}$ For confidentiality reasons, the experimental results section does not show images or data related to the factory tests and validations, but those carried out in the facilities of the $R \& D$ group.
} 


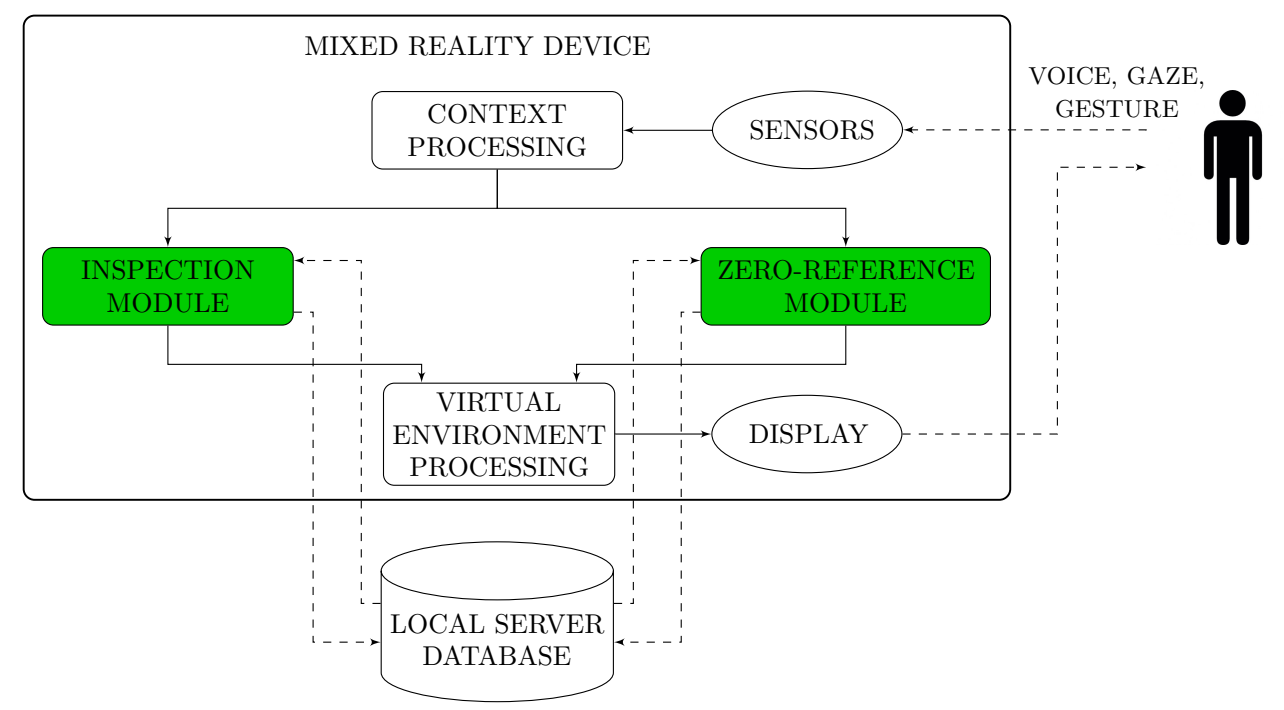

Fig. 6. Block diagram of the proposed MR-based user interface for quality control of car body surfaces.

Fig. 6: the zero-reference and inspection modules. Both modules have access to the local server database and read/write permission according to the worker credentials. With respect to these credentials, a maintenance user is defined, who has full read/write permissions and access to all functionalities of the application, and a worker user, who has restricted application functionalities, such as the zero-reference module or the system communication management.

Next, the zero-reference and inspection modules, as well as the multiagent capability of the proposed MR-based user interface are fully described.

\subsection{Zero-reference module}

MR devices such as Microsoft ${ }^{\circledR}$ HoloLens glasses need to be calibrated in order to allow the device to adjust stereographic projections [37] according to the user's interpupillary distance (IPD). With an incorrect IPD, virtual objects may appear unstable or at an incorrect distance. In addition, these devices are equipped with spatial mapping capabilities that allow, together with SLAM techniques [38, 39], to perform a reconstruction of the environment in which the device is immersed, and create a convincing MR experience (see the following link [40] for more details). Virtual objects are placed 
Table 2. MR user-based interface functionalities.

\begin{tabular}{|c|c|c|}
\hline \multirow{12}{*}{ MAIN MENU } & \multirow{2}{*}{$\begin{array}{l}\text { CAR BODY IDENT. } \\
\text { NUMBER SECTION } \\
\text { (INPUT BY GESTURE) }\end{array}$} & $\begin{array}{l}\text { MANUAL SETTING } \text { BY WORKERS } \\
\text { FROM DATA BASE }\end{array}$ \\
\hline & & $\begin{array}{l}\text { STREAM DATA FROM DEFECT DETEC- } \\
\text { TION SYSTEM }\end{array}$ \\
\hline & \multirow{5}{*}{$\begin{array}{l}\text { INFORMATION } \\
\text { SECTION (INPUT BY } \\
\text { GESTURE) }\end{array}$} & NUMBER OF DEFECTS \\
\hline & & CAR BODY IDENT. NUMBER \\
\hline & & CAR BODY COLOR \\
\hline & & CAR MODEL \\
\hline & & DATE \\
\hline & \multirow{5}{*}{$\begin{array}{l}\text { OTHER FUNCTIONS } \\
\text { (INPUT BY GESTURE) }\end{array}$} & ADD NEW DEFECTS \\
\hline & & CAD MODELS VISIBILITY \\
\hline & & AUTOMATIC/MANUAL MODES \\
\hline & & GO TO ZERO-REFERENCE MENU \\
\hline & & TCP/IP COMMNUNICATION SECTION \\
\hline \multirow{11}{*}{ DEFECT MENU } & \multirow{3}{*}{$\begin{array}{l}\text { CAR BODY } \\
\text { INFORMATION (INPUT } \\
\text { BY VOICE OR } \\
\text { GESTURE) }\end{array}$} & CAR BODY IDENT. NUMBER \\
\hline & & CAR MODEL \\
\hline & & $\begin{array}{l}\text { DEFECT INFORMATION FROM DE- } \\
\text { FECT DETECTION SYSTEM }\end{array}$ \\
\hline & \multirow{4}{*}{$\begin{array}{l}\text { DEFECT } \\
\text { INFORMATION SET BY } \\
\text { WORKER (INPUT BY } \\
\text { VOICE OR GESTURE) }\end{array}$} & TYPE \\
\hline & & CATEGORY \\
\hline & & SIZE (ACCORDING TO THE WORKER) \\
\hline & & STATUS (REPAIRED/NOT REPAIRED) \\
\hline & \multirow{4}{*}{$\begin{array}{l}\text { DEFECT RESUME (BY } \\
\text { POINTING AT THE } \\
\text { DEFECT) }\end{array}$} & NUMBER \\
\hline & & TYPE \\
\hline & & CATEGORY \\
\hline & & SIZE \\
\hline \multirow{3}{*}{$\begin{array}{l}\text { ZERO- } \\
\text { REFERENCE } \\
\text { MENU }\end{array}$} & \multirow{3}{*}{$\begin{array}{l}\text { MANUAL ADJUST } \\
\text { (INPUT BY GESTURE } \\
\text { \& VOICE FEEDBACK) }\end{array}$} & TRANSLATION [mm] \\
\hline & & \\
\hline & & ROTATION [degree] \\
\hline
\end{tabular}


within the user environment according to the result of this spatial mapping. In order to avoid introducing landmarks around the environment, the spatial mapping marker-less is commonly used [41]. However, the accuracy and performance of this spatial mapping can vary depending on the environment conditions of light, number of moving objects around, and other factors. This will affect directly to the location and stability of all the virtual objects.

Therefore, in order to mitigate the accuracy error of the spatial mapping, this work proposes to use zero-reference landmarks in order to set all the virtual objects projected within the environment with respect a global reference system. In this way, if the user determines that there are significant errors in the location of the virtual objects within the environment, a reset is available to reposition all the virtual objects according to the global reference system given by the landmarks. Hence, the application is more robust and can be used in industrial environments.

The zero-reference module developed in this work is shown in Fig. 7. When this module is activated, the system waits for the worker to gaze at all required landmarks placed around the workspace. When all landmarks are detected correctly, the global reference coordinate system is set and all the virtual objects will be positioned accordingly with this reference systems. Once the global reference coordinate system is obtained, a query is made to the local server database in order to load all the virtual objects into the environment, according to previous setups. If there were errors in the location of the virtual objects, the user could modify the position of each of the virtual objects coordinate systems with respect to the reference coordinate system, reducing the error and improving the location accuracy of the virtual objects within the real environment.

Concretely, in this specific application a virtual body is used as reference for the rest of the virtual objects coordinate systems, which is located in the inspecting position, where a real car body of the same model is required for the fine adjustment of the virtual objects coordinate systems with respect the global reference system. The position and orientation of the virtual body can be modified by the user in order to match the virtual model with the real reference car body. For this purpose, reference features of the car body are used, such as the hollows of the handles, the windows, style lines, etc. Thus, the user criterion for a good set-point is that the error between virtual and real car body features is minimal. Once the user agrees with the result of the matching, the new location of the virtual objects coordinate systems with respect to the global reference coordinate system is stored into the local 


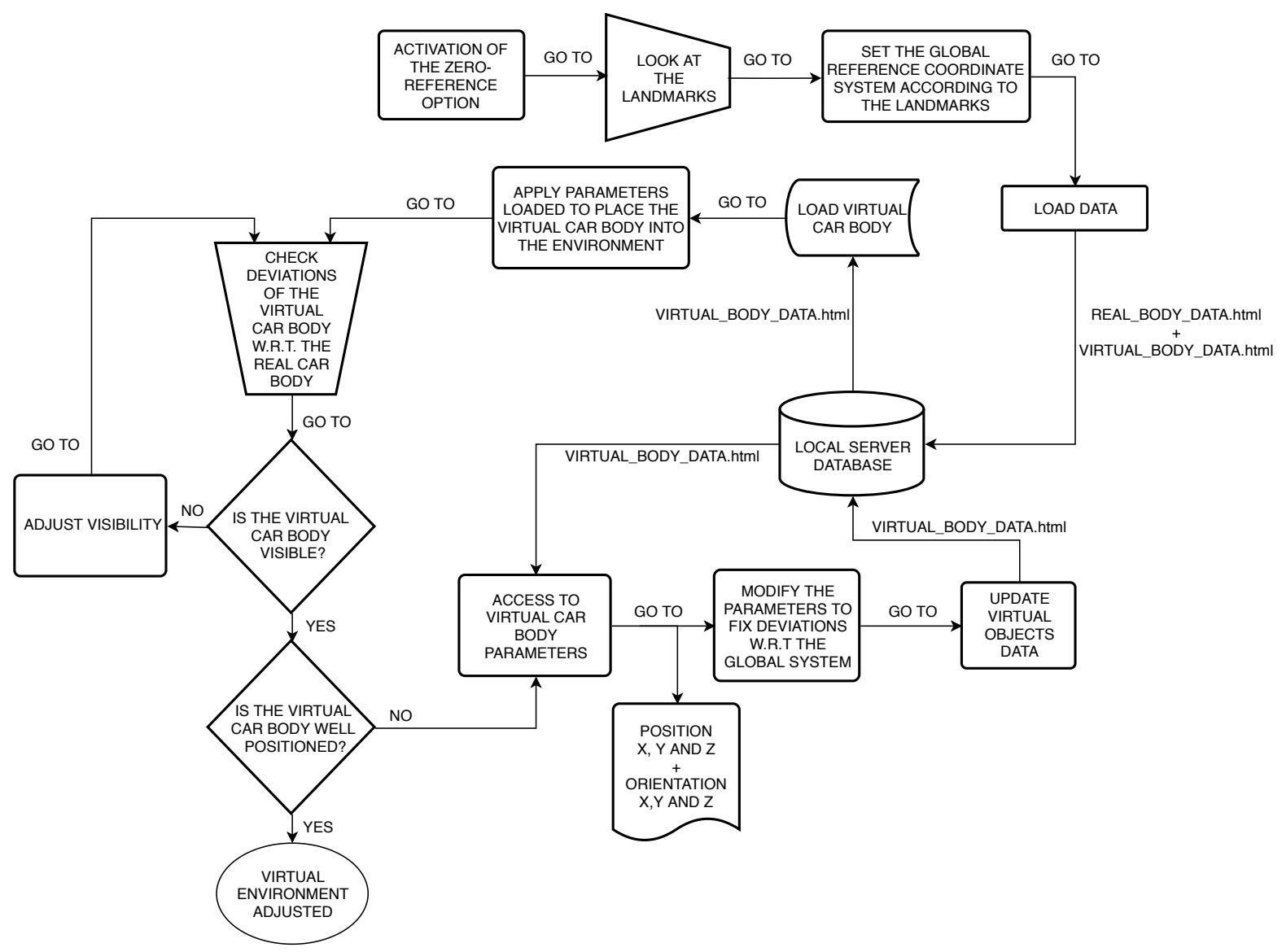

Fig. 7. Zero-reference module flowchart. When the module is activated: firstly, the user is requested to look at the required landmarks; once all required landmarks have been properly detected by the system, the global reference system is set within the environment, the virtual car body is placed with respect to this global reference system and previous parameter adjustments are loaded from the local server database; then, the user can adjust the coordinate system of the virtual car body in order to mitigate position errors with respect the real car used as reference; finally, all the adjustments are saved in the local server database. 
server database in order to be used by all MR devices in the network.

The zero-reference module can only be utilized by users with maintenance worker credentials. In this way, unauthorized workers are prevented from making changes that could lead to system malfunctions.

\subsection{Inspection module}

According to the functionalities that the application must have (see Table 2), Fig. 8 shows the inspection module flowchart developed for this purpose. When this module is selected, the worker can choose the automatic or manual inspection options. In the automatic inspection option, the application waits for the car body identification number provided by the production line controllers. Once the car body identification number is provided, a query is made to the local server database that transmits all inspection results (i.e., location of defects, characteristics, etc.) and other required information to the MR device. This information is managed by the MR-based user interface developed in order to project the corresponding virtual objects into the workspace (i.e., colored spheres on the car body surface indicating the presence of defects). When the worker gazes at a defect, a virtual screen appears showing the basic characteristics of the defect, such as size, typology, etc. At this moment, the worker is able to modify the data associated to the defect: the worker can modify the size, the typology and even its state (i.e., repaired, without validating, etc.). Note that, in order to validate the defect characteristics, the worker must approach to the surface and see the defect. For this purpose, when the worker approaches to the body surface, all virtual objects disappear, allowing thus the visibility of the defect.

It is worth to mention that current automatic detection systems are focused on detecting small structural defects produced by dirt $[1,2,3]$. This typology comprises about the $80 \%$ of the total of defects found in car bodies [4] and, together with the difficulty of being detected by humans, the majority of these systems are focused on the correct detection of this typology of defects. For doing this, vision-based defect detection systems use the "deflectometry" principle [27, 42], which allows to highlight small defects produced by dirt, but hide non-structural defects, such as talk marks and paint shadows, among others. Furthermore, the detection of the mentioned small defects can fail (see $[33,3]$ for more details). Therefore, since the automatic defect detection system can fail due to all these issues, the proposed inspection module allows the workers to add the location of defects that have not been detected by the automatic defect detection system. 


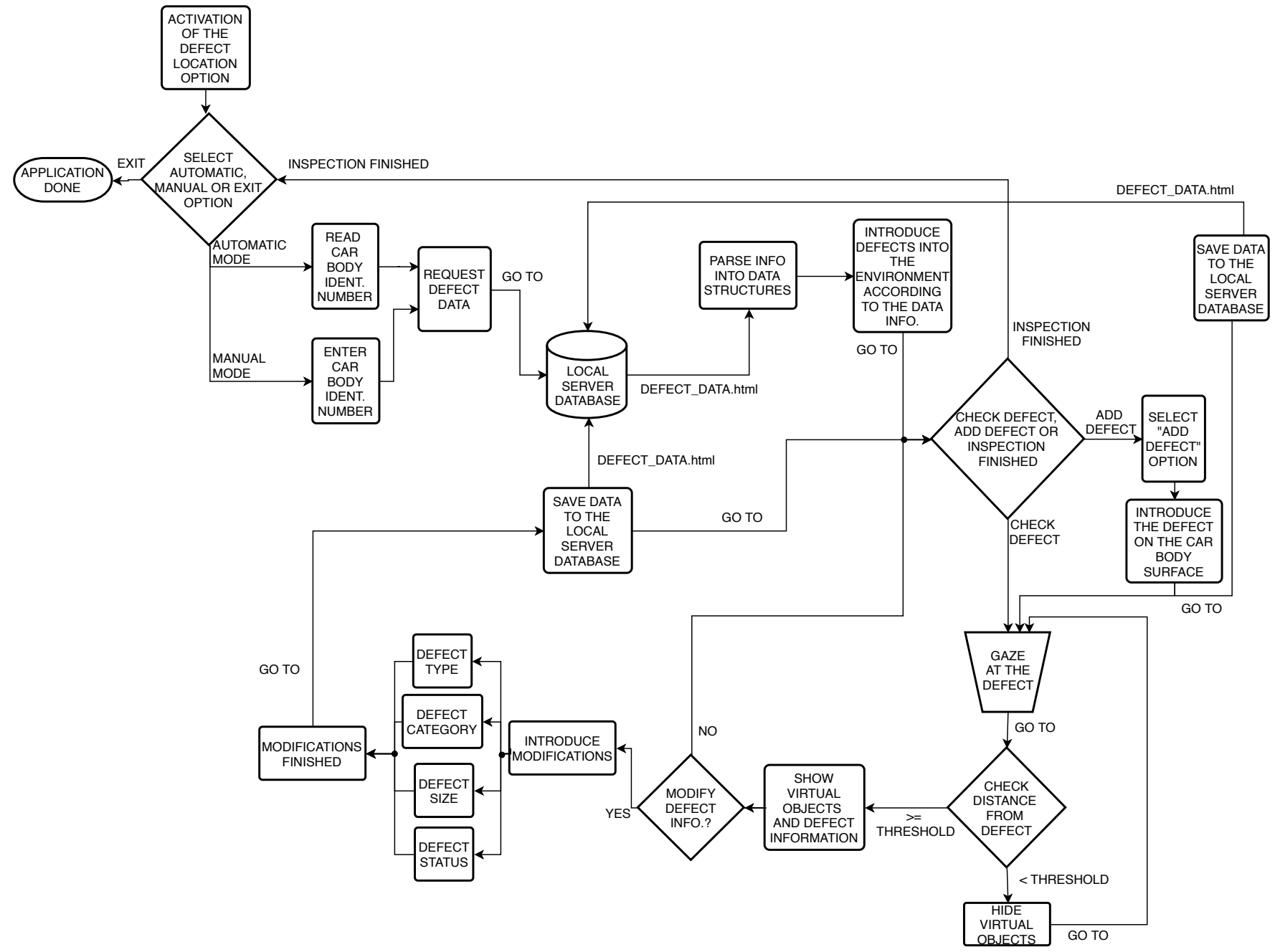

Fig. 8. Inspection module flowchart. When this module is activated: first, automatic and manual options can be selected; when automatic mode is chosen, the car body identification number is given by the factory systems, whilst if the manual option is selected, the car body identification number is introduced by the user; given the car body identification number, all needed data is loaded from the local server database and users can see the locations of the defects on the car body; the user can then check the defects, modify their data and add new defects; once the inspection is finished, the data is stored into the local server database. 
Once the appropriate changes are made and validated by the worker, these changes are sent to the local server database so that other workers can update the virtual objects information according to the changes introduced. When the location of a new defect is added, the worker can change its characteristics following the same procedure explained above. This new defect is stored in the local server database.

In the manual inspection option, the worker introduces the car body identification number of the corresponding car body to be inspected. The rest of the flowchart is the same as in the automatic inspection option.

\subsection{Multi-agent capability}

In order to meet the cycle times required by the production line and due to the size of the car bodies (e.g, $20 \mathrm{~m}^{2}$ for small cars up to $60 \mathrm{~m}^{2}$ for minivans), the car body surfaces are inspected by a group of 4-8 workers. That means that each worker must use a MR device, which belongs to a working network (see Fig. 9(a)). To prevent two or more workers from checking the same defect or from checking defects already inspected by other workers, it is proposed to equip the system with multi-agent capabilities.

Fig. 9(b) shows the proposed flowchart of the application. Each device sends a flag to indicate its presence to the local server, which will give access to the local server database, when possible. If a worker requests the access to the local server database and it is locked, the local server sends the notification "permission denied" in order to avoid simultaneous accesses to the local server database for security reasons. Alternatively, other communication architectures could be considered, as long as they meet the industrial automotive plant standards, in order to allow concurrent reads with writes, e.g., the so-called Representational State Transfer (REST) architecture. However, this is out of the scope of this research and remains as further work. This permission will depend on the worker credentials and the number of devices connected. If a device requires access to the database, the local server keeps it waiting until the database is not being used/modified by any other device. Once the database is available, the device can perform the required operation, that is, consult or modify the database. Finally, when the database query is done, the database is released and the information is updated to all the devices that are currently connected. 


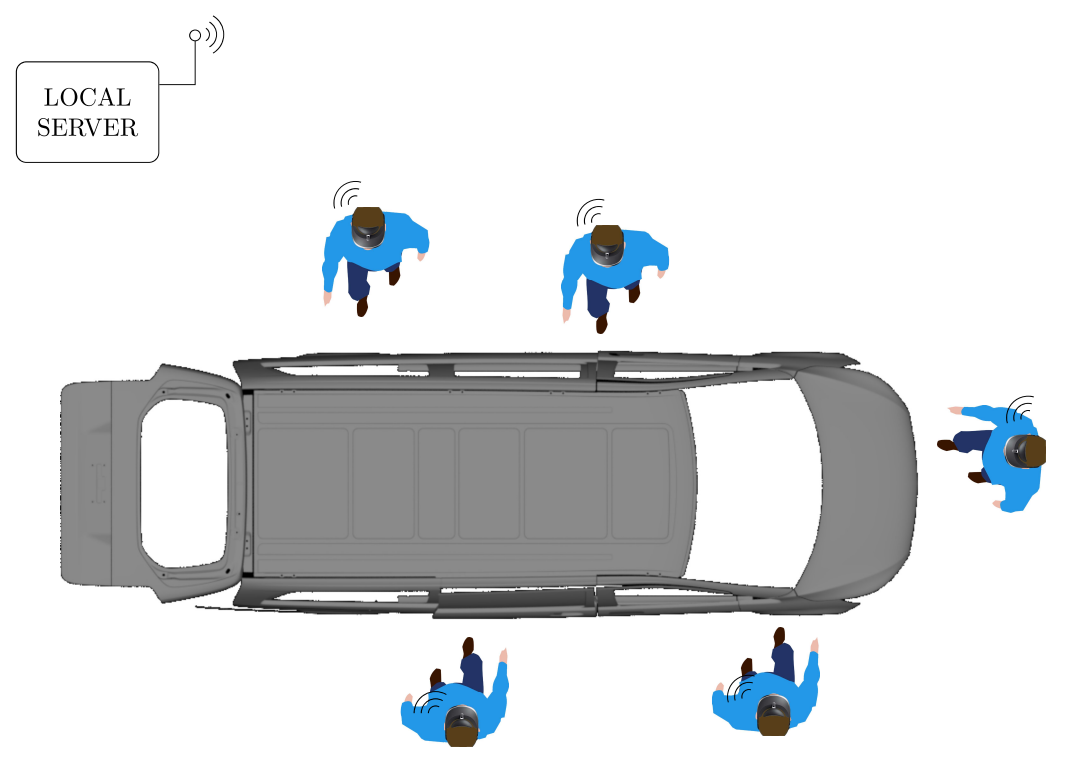

(a) Multi-agent network.

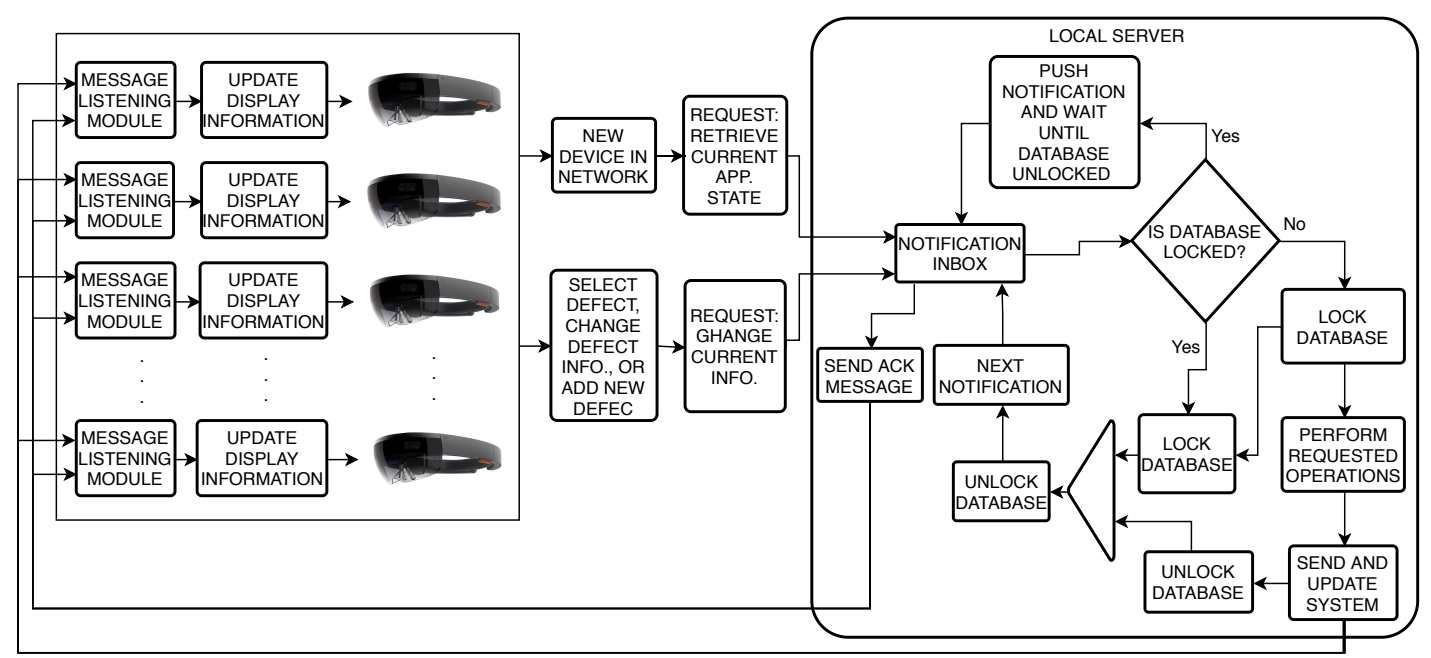

(b) Flowchart.

Fig. 9. Multi-agent MR based-user interface for quality control of car body surfaces. 


\section{Results}

\subsection{Experimental results of the industrial prototype}

First, it is worth noting that the defect detection systems or algorithms used to automatically detect the defects on a car body are out of the scope of this research. However, the reader is referred to the bibliography $[1,2,3$, $4,5,6,7]$ to learn the specific details about these automatic defect detection systems.

To demonstrate the feasibility of the proposal made in this paper, the MR-based user interface has been developed on the Microsoft ${ }^{\circledR}$ HoloLens glasses [43, 44], although other MR devices could be used, provided that their technical specifications are similar or superior to those offered by the Microsoft ${ }^{\circledR}$ HoloLens glasses.

Fig. 10 shows the experimental setup utilized for the industrial demonstration, which consists of: a defect detection system for automatic defect detection; a car body with known defects of all typologies and sizes; a Microsoft ${ }^{\circledR}$ HoloLens glasses; and an artificial landmark. Additionally, as external local server, an industrial PC was used. The communication between this local server and the Microsoft ${ }^{\circledR}$ HoloLens glasses was based on TCP/UDP protocol. The proposed MR-based user interface was designed and all its functionalities were programmed using the following software: Visual Studio 2017 was used as integrated development environment (IDE), Blender 2.7 as 3D modeling suite [34], and Unity LTS release 2017.4 [35] with back end IL2CPP as 3D game platform using tools such as MixedRealityToolkit-Unity [45] and Vuforia engine ${ }^{\circledR}$ [46].

A video has been recorded to show the main functionalities of the MRbased user interface developed in this work. Fig. 11 shows several frames of the video that can be played following this link [47]. First, the automatic defect detection system performs the inspection process, whose results are stored in the local server database. Note that the minimum information stored, independently of the automatic defect detection system used, is the Cartesian location of the defect and its size. With this minimum information, it is possible to discriminate by size the defects that, although existing, are within the standard of the car manufacturer, whilst with the location, the defects that are not within the standard can be located by the workers to be repaired. Once the car is in the inspection position, the worker can see the main menu above the car body (see Fig. 11(a)). Note that this menu is always visible by the worker since the main functionalities of the application 


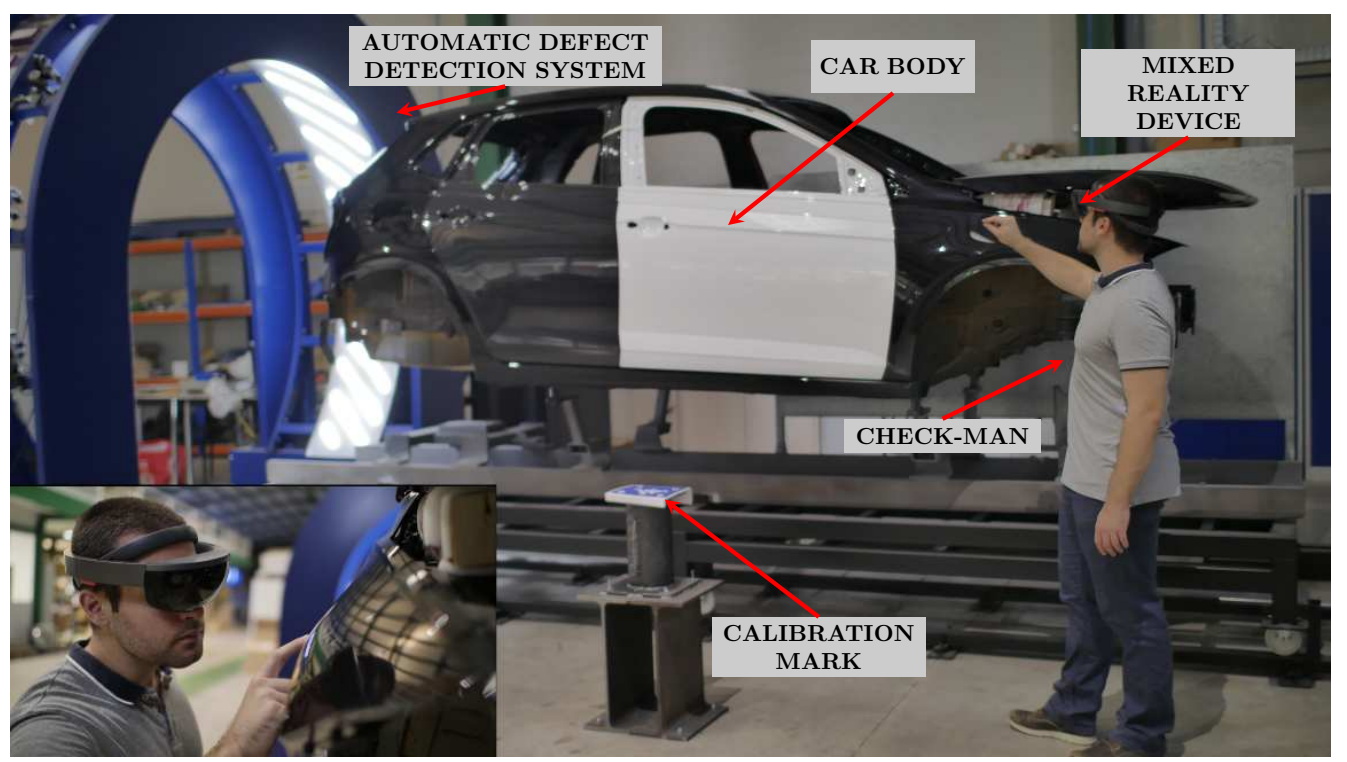

Fig. 10. Experimental setup.

are available in the menu. Once the car body identification number is read by the server, results of the inspection are sent to the Microsoft ${ }^{\circledR}$ HoloLens glasses and virtual red spheres are located all around the car body, indicating the presence of defects (see Fig. 11(b)). The worker can then see the main characteristics of a concrete defect gazing with the eyes at the defect (see Fig. 11(c)). Note that the color of the defect changes from red to gray and a floating menu appears showing the values of the main characteristics. By "airtapping" (i.e., a gesture made with the index and thumb fingers) at the chosen defect, a floating menu with all the editable information (see Tab. 2) of the defect appears (see Fig. 11(d)). Note that, in order to edit the information of a defect, the worker has to check the defect. For this reason, when the distance from worker to the car body is below a given threshold, all virtual objects are hidden, allowing the worker to check the defect free of disturbances (see Fig. 11(e)). Then, the worker can introduce or modify the information of the defect by "airtapping" to the different chooses in the defect menu. When this menu is closed by the worker, the information is updated to the local server database, allowing thus being seen by other workers of the network. If a defect is not automatically detected by the defect detection system (see Fig. 11(f)), it can be introduced manually by 


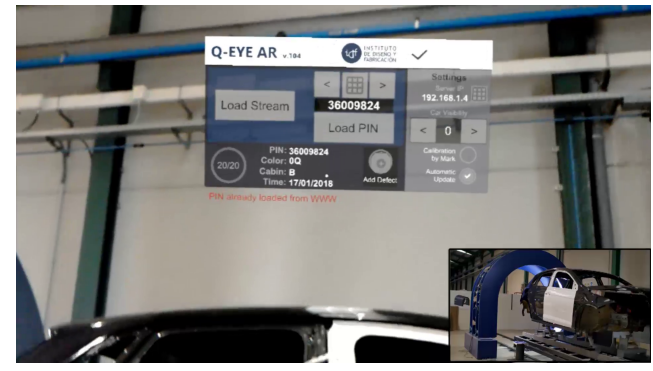

(a) Frame at $0 \mathrm{~m} 44 \mathrm{~s}$.

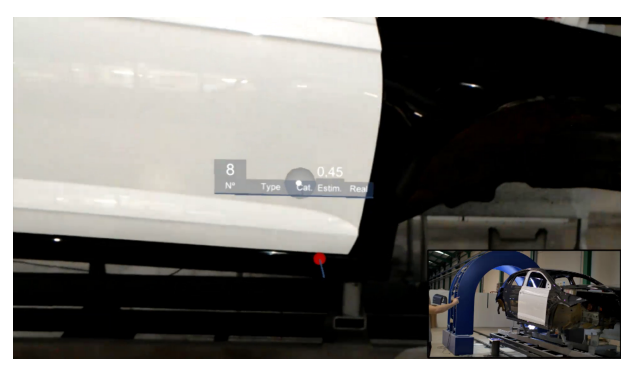

(c) Frame at $0 \mathrm{~m} 54 \mathrm{~s}$.

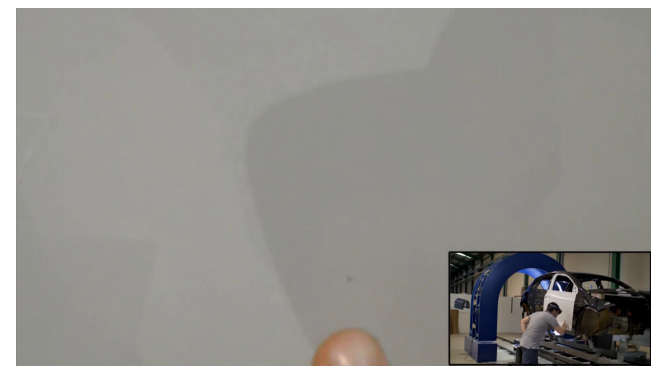

(e) Frame at $1 \mathrm{~m}$ 01s.

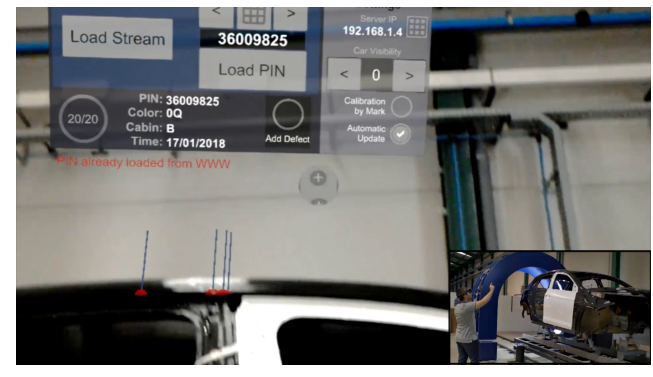

(g) Frame at $1 \mathrm{~m} 32 \mathrm{~s}$.

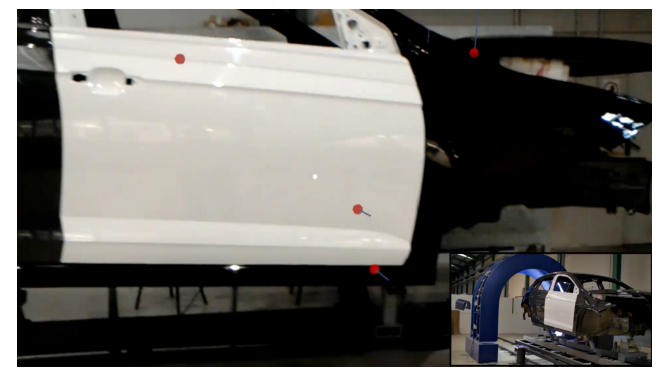

(b) Frame at 0m 51s.

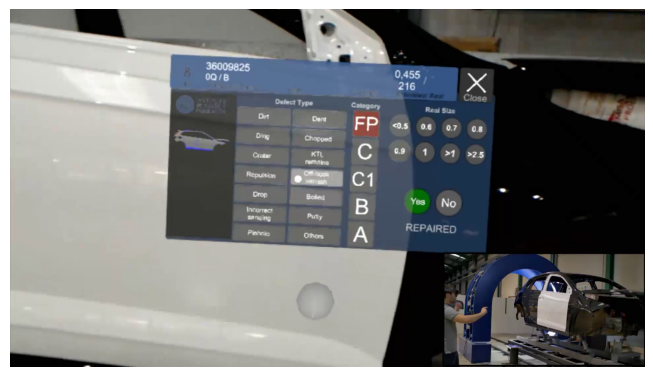

(d) Frame at $0 \mathrm{~m} 56 \mathrm{~s}$.

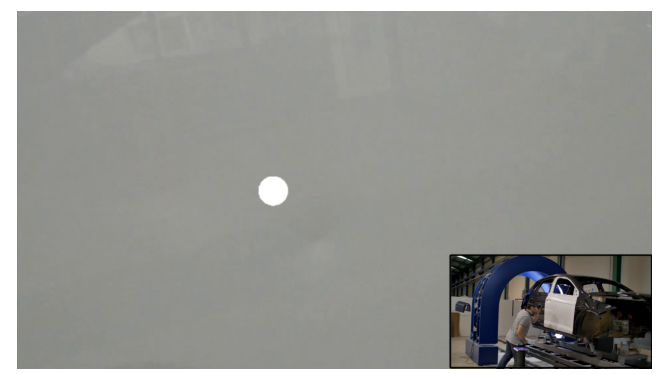

(f) Frame at $1 \mathrm{~m} 24 \mathrm{~s}$.

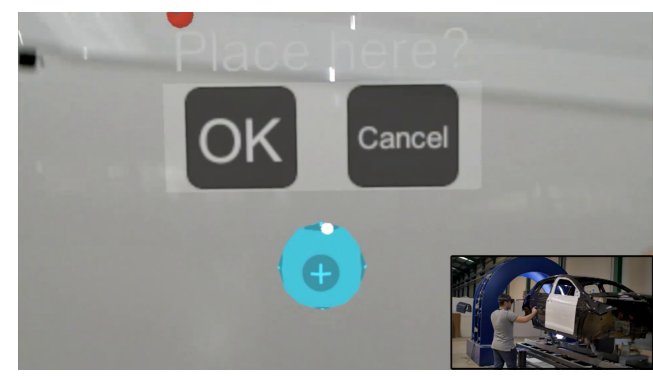

(h) Frame at $1 \mathrm{~m} 41 \mathrm{~s}$.

Fig. 11. MR-based user interface industrial demonstration (video [47]). 
the worker using the option of "add new defect" present in the main menu (see Fig. 11(f)). By "airtapping" this functionality, a gray sphere is then selected and easily handled by the worker to the location of the defect (see Fig. 11(g)). When the worker agrees with the location, the confirmation is carried out by "airtapping" (see Fig. 11(h)). The information of this new defect can be introduced following the same procedure explained above.

Another video has been recorded to show the robustness of the MR-based user interface application developed with respect to changes in the workspace. Fig 12 shows frames from the video that can be played following this link [48]. The video also shows the capability of hiding or viewing the 3D model of the car body, which is mainly used to modify all the virtual objects coordinate systems with respect to the global reference system during the setup stage ${ }^{2}$.

\subsection{Usability analysis}

Accordingly with $[51,52,53]$, different methodologies such as usability tests of applications, commonly used in the verification of hardware and software, along with surveys and in-depth interviews were used to evaluate and validate the effectiveness of the proposed MR-based user interface compared with actual 2D interfaces implemented on PADs, currently used in factories such as Mercedes-Benz. Concretely, the System Usability Scale (SUS) questionnaire [54] was carried out. Additionally, the users were given the opportunity to write down comments and suggestions in order to obtain more information apart from the SUS questionnaire. Two different tests were carried out: Test A was developed to analyze the advantages and drawbacks of each interface when the worker deals with information given by the automatic defect detection system, having to locate the given defect on the surface, mark it and store its typology in the local server database; Test B was developed to analyze the advantages and drawbacks of each interface when the worker has to introduce new defect information to the local server database, i.e., defects that are not detected automatically by the defect detection system.

The tests were performed by 41 users with and without experience in car body surface quality control. In this way, the evaluation will reflect the

\footnotetext{
${ }^{2}$ More demonstrative videos can be played at the following links: demonstration explaining the defect menu (see this video [49]); demonstration explaining the main menu (see this video [50])
} 


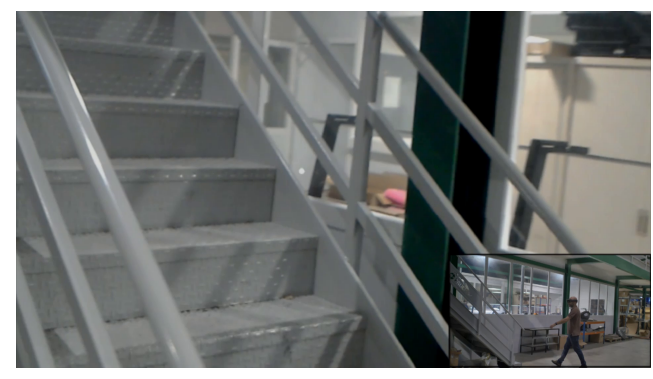

(a) Frame at 10s.

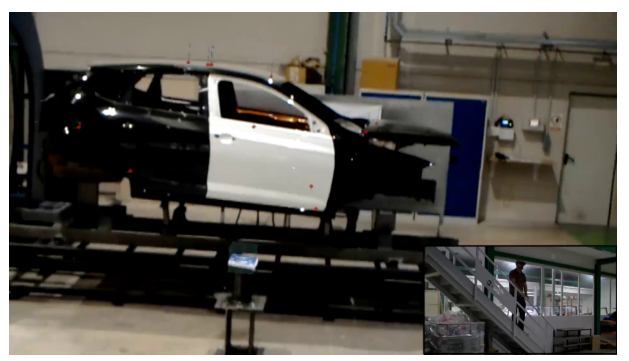

(c) Frame at $27 \mathrm{~s}$.

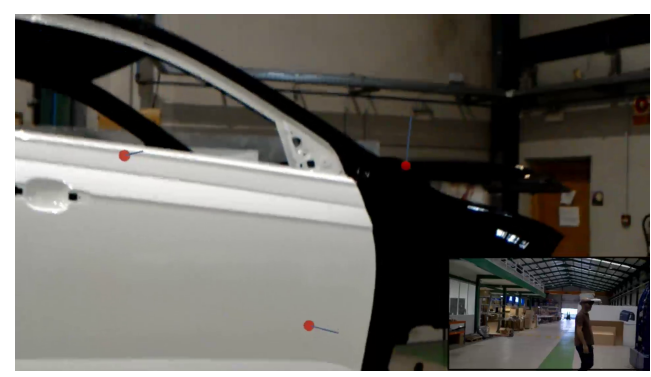

(e) Frame at 35s.

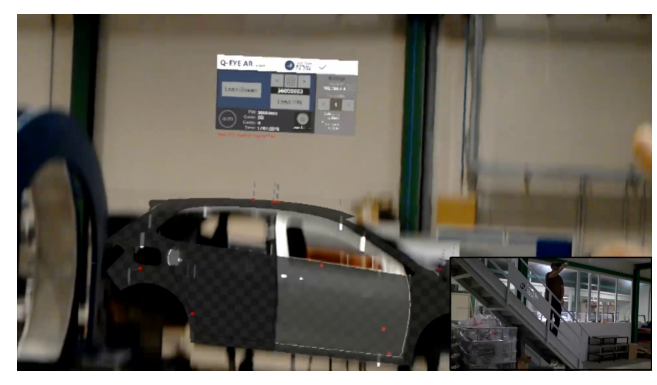

(b) Frame at 20s.

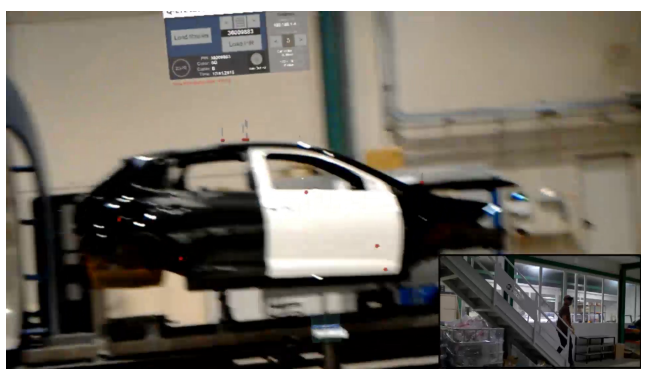

(d) Frame at 29s.

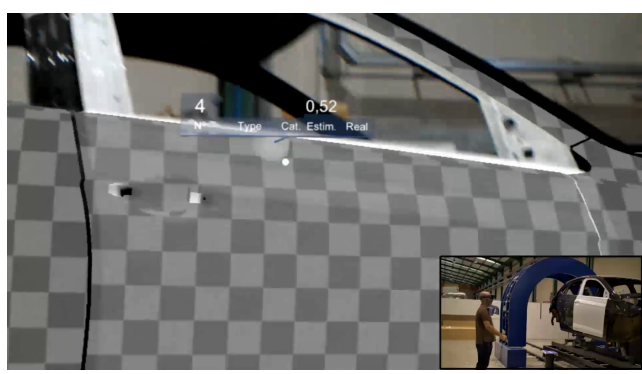

(f) Frame at $44 \mathrm{~s}$

Fig. 12. MR-based user interface robustness demonstration (video [48]). 
extent to which the application is intuitive. For this purpose, the industrial interface is simplified as follows:

- Non needed application options, such as set-point menu, main menu, etc., are removed.

- Four typical typologies are considered: Paint, as small defects such as the ones produced by dirt; Dings; Scratches; and False positives, as defects indicated by the automatic defect detection system which do not exist in the reality.

- Defects are shown and analyzed by users one by one. In the industrial application all defects are shown at the same time and the worker decides the order to be considered.

Fig. 13 shows the experimental set-up used for the usability questioner. Test A set-up is shown in Fig. 13(a), which is composed of a black hood with known defects, a camera ceiling mounted in order to monitory the results of each experiment, and green magnetic circles were used to mark the location of each defect. The user's objective is to observe a virtual image of the defect location given by the local server database, locate it and mark it on the real surface's hood, classify it and update the local server database with the result of this classification. Table 3 shows the 9 different defects that users had to face with. For each user it has been measured the time employed to perform the task and the success in locating the given defects and classifying their typology.

The Test B set-up is shown in Fig. 13(b), which is composed of a dark blue hood with known defects and yellow magnetic circles used to mark the location of each defect. The user's objective is to introduce to the system the location of a series of already marked defects on the hood. The purpose of this test is to measure the accuracy and ease of the user when introducing the location of new defects. The accuracy of the defect location is measured through the error between the reference location of the defect and the location of the defect introduced by the user. This error is measured in $2 \mathrm{D}$ in the case of using the PAD-based interface, and in 3D in the case of using the MR-based interface.

Fig. 14 shows the ideal results used as reference in the tests. Thus, the user success in the tests is obtained comparing these ideal results with the defect locations marked by the user. In Test A, the comparison is computed 


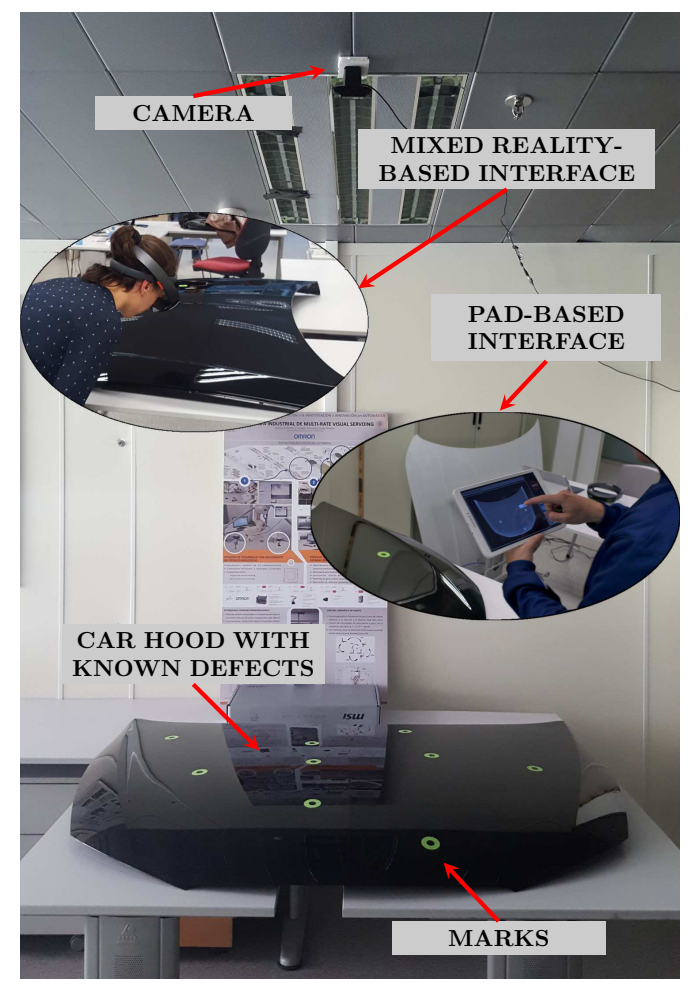

(a) Test A.

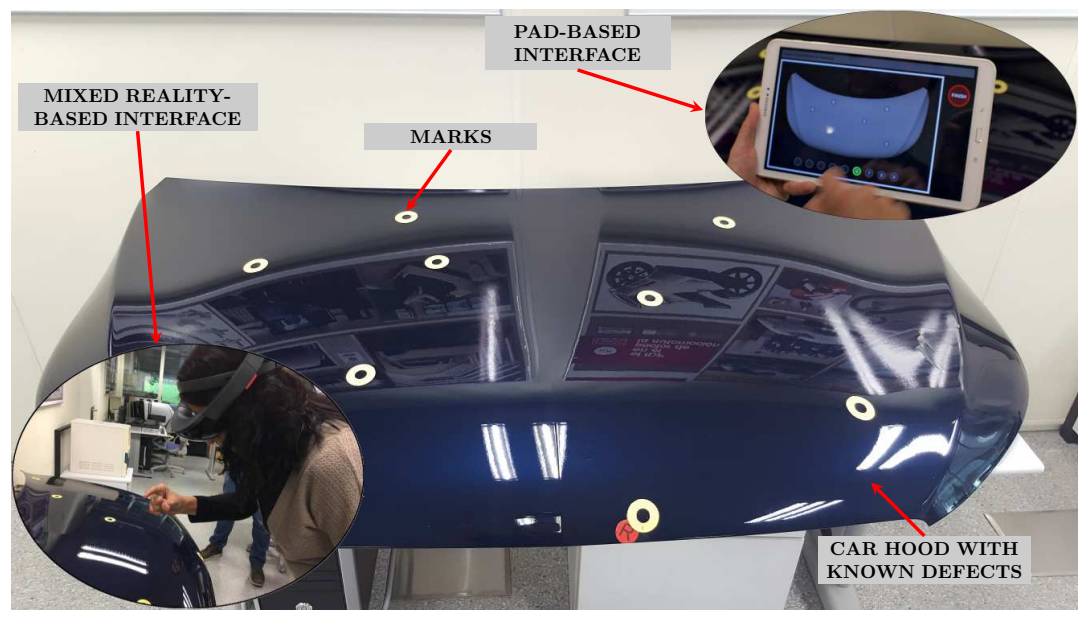

(b) Test B.

Fig. 13. Experimental set-up for the usability tests. 
by applying image processing to a photo taken by a ceiling-mounted camera (see Fig. 14(a)). In Test B, the comparison is computed through a 2D model in the case of the PAD interface (see Fig. 14(b)) or 3D model in the case of the MR interface (see Fig. 14(c)). In the case of the PAD interface, the $2 \mathrm{D}$ model is obtained from the results given by the image processing algorithms in [4]. In the case of the MR interface, the 3D model is obtained by matching the virtual objects with the real targets, being the SLAM and spatial mapping algorithms of the MR device in charge to update the location of all virtual objects with respect the user location.

The following devices were used in order to compare current worker interfaces with the proposed MR-based user interface: a Samsung's Galaxy Tab A SM-T580 as PAD with the application adapted to this platform is compared to the application running in the Microsoft ${ }^{\circledR}$ HoloLens glasses as MR device.

Fig. 15 shows the main information about the 41 users who performed the usability tests. Note that $97.56 \%$ of the users (i.e., all but one user) were frequent PAD users, whilst $68.29 \%$ of them had never used MR devices. All users were trained during 10 minutes before the tests with both platforms in order to introduce them to the application and devices.

Fig. 16 shows the results for Test A. A video demonstrative of the test using the PAD can be played following this link [55] and using the MR device with this link [56]. A total of 41 users performed this test: 21 for the MR device and 20 for the PAD device. In Fig. 16(a) can be seen how, in general, users have been more successful classifying the defects with the use of the PAD than using the proposed methodology based on MR. This may be due to the fact that, although the HoloLens device allows to see the physical reality, its lenses overshadow the light, making it difficult the vision of the defects ${ }^{3}$. Another factor that may affect is the fact that the MR application and device offer a high novelty to most of the users, misleading them of the task to be performed. However, these issues may be reduced (or eliminated) as the user becomes more familiar with the MR technology, leading to an improvement of the user performance, e.g., see the usability studies described in [57]. This is also indicated in the time needed to perform the task shown in Fig. 16(b)

\footnotetext{
${ }^{3}$ Note that the more effective method to see defects on specular car body surfaces is to use different directions of light in order to identify the changes produced by the surface deformations [3]. Both light intensity and direction are critic in this method.
} 


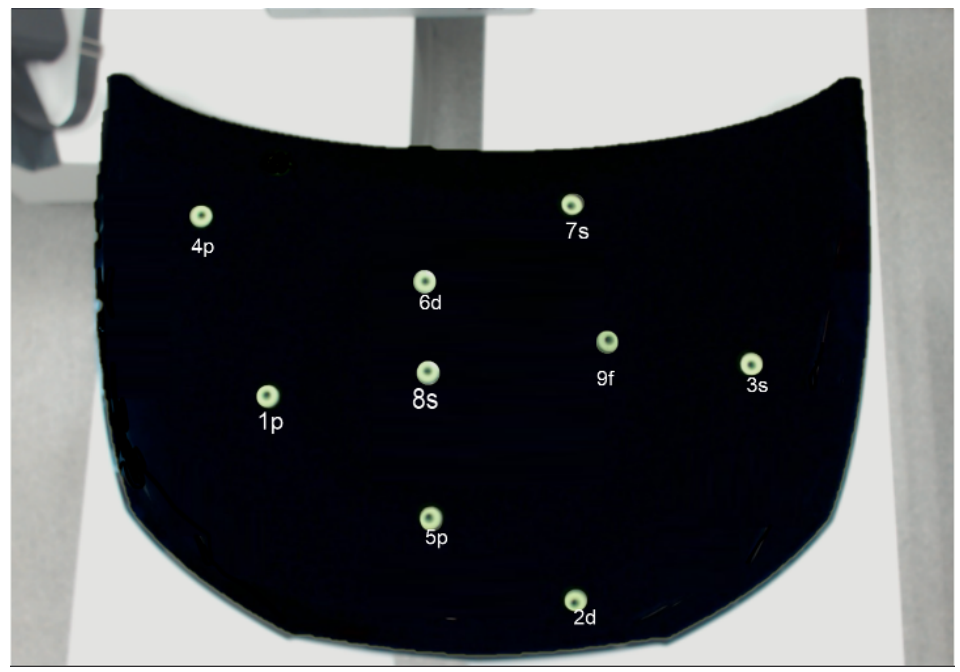

(a) Test A: the letters refer to the type of the defect ("p" means paint, "s" means scratch, "d" means dent and "f" means false).

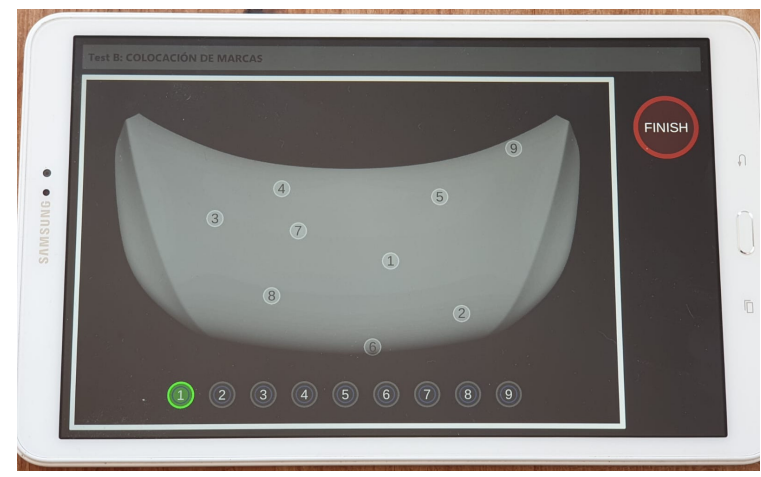

(b) Test B with the PAD device.

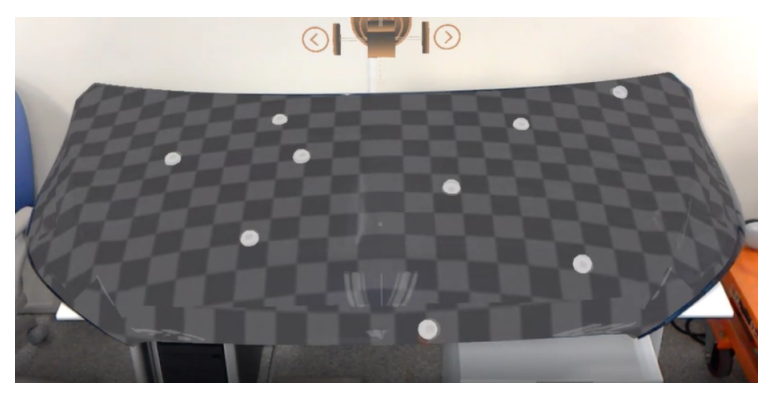

(c) Test B with the MR device.

Fig. 14. Ideal results used as reference in Test A and Test B: the numbers from 1 to 9 indicate the order in which each defect has to be introduced by the user. 
Table 3. Characterization of the defects used in Test A and Test B.

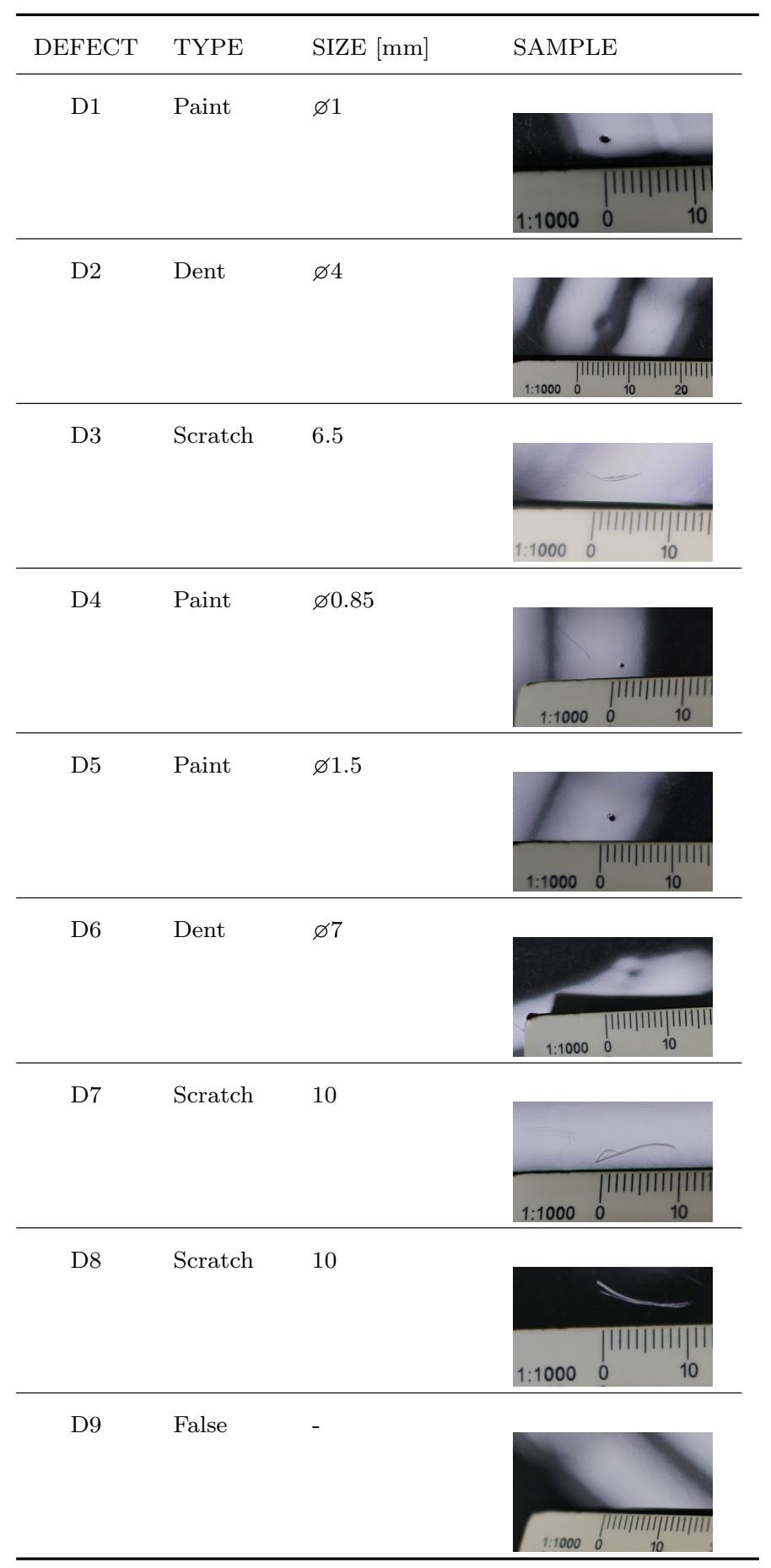



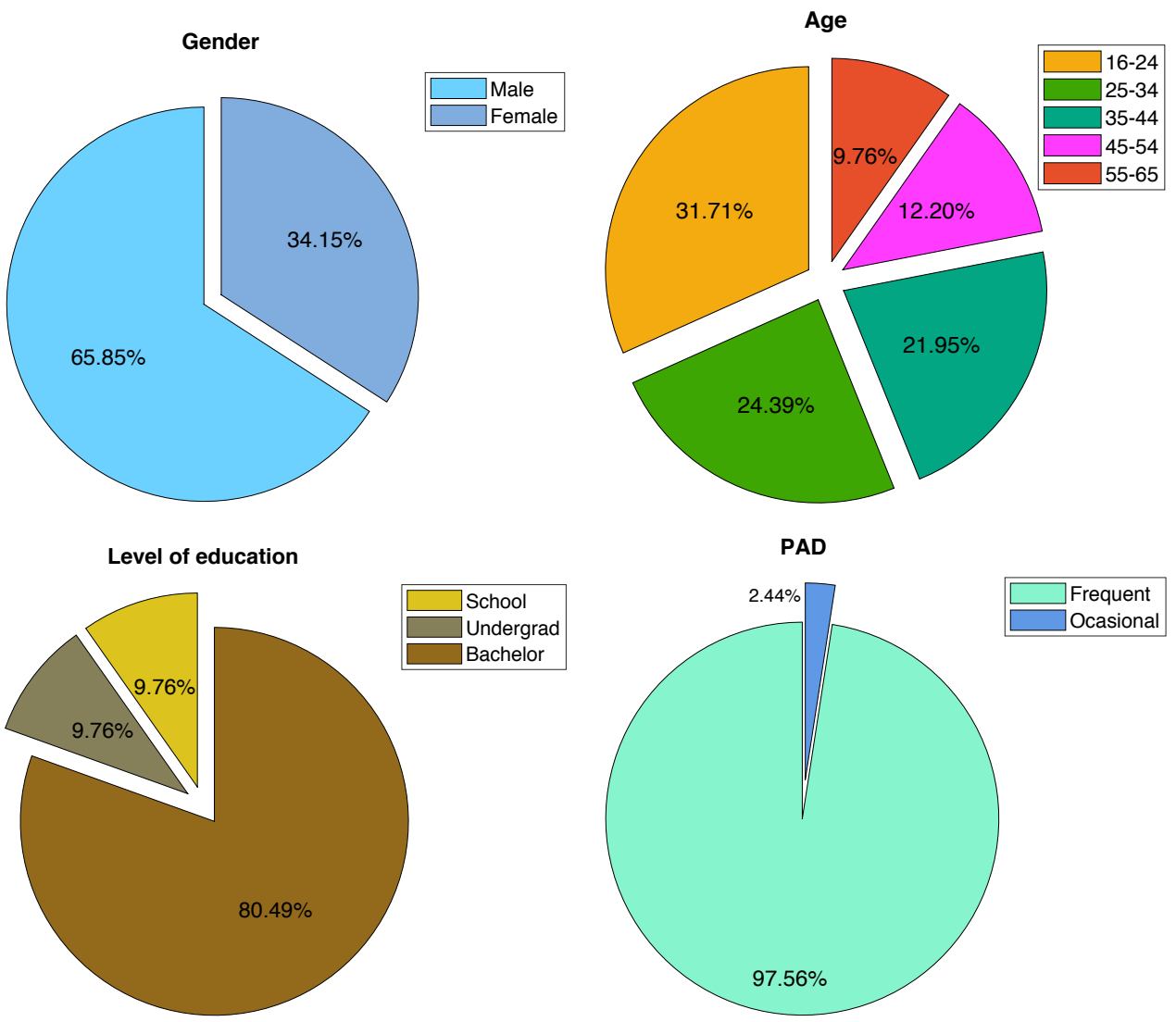

Mixed reality device user

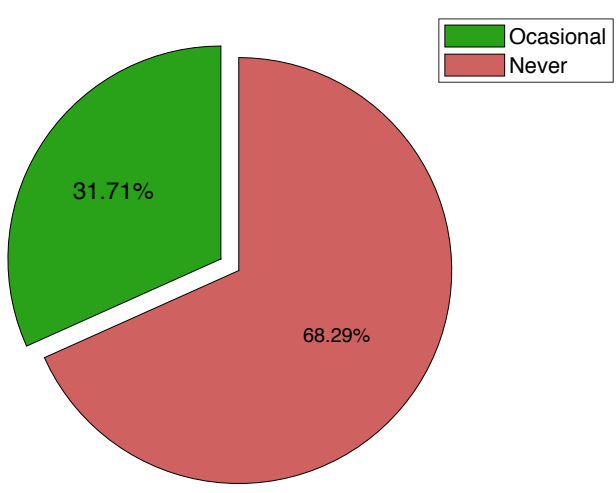

Fig. 15. Main information of the users: a total of 41 users, of whom 21 performed both Test A with the MR device and Test B with the PAD device, and 20 performed both Test $\mathrm{B}$ with the MR device and Test A with the PAD device. 

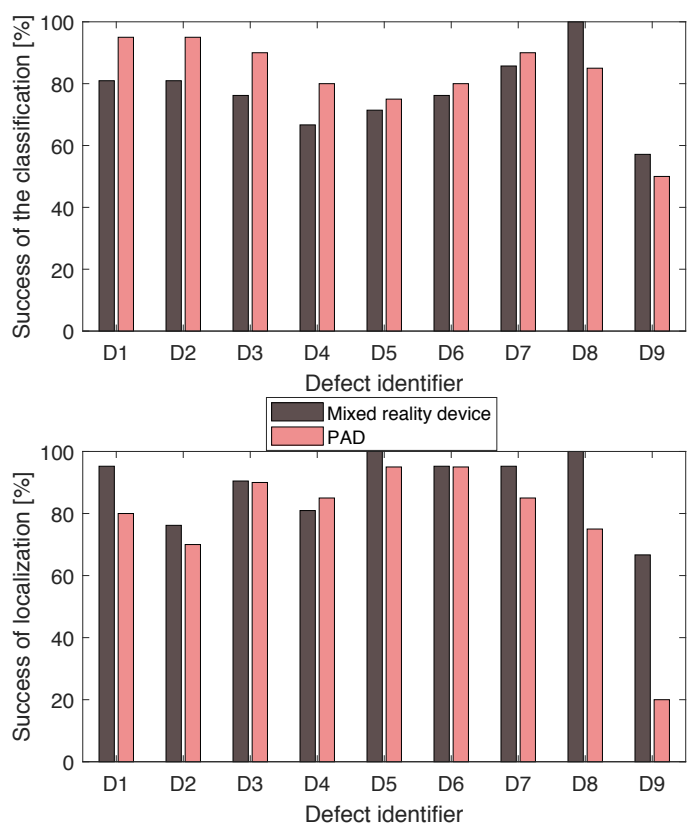

(a) Success in locating and classifying the given defects.
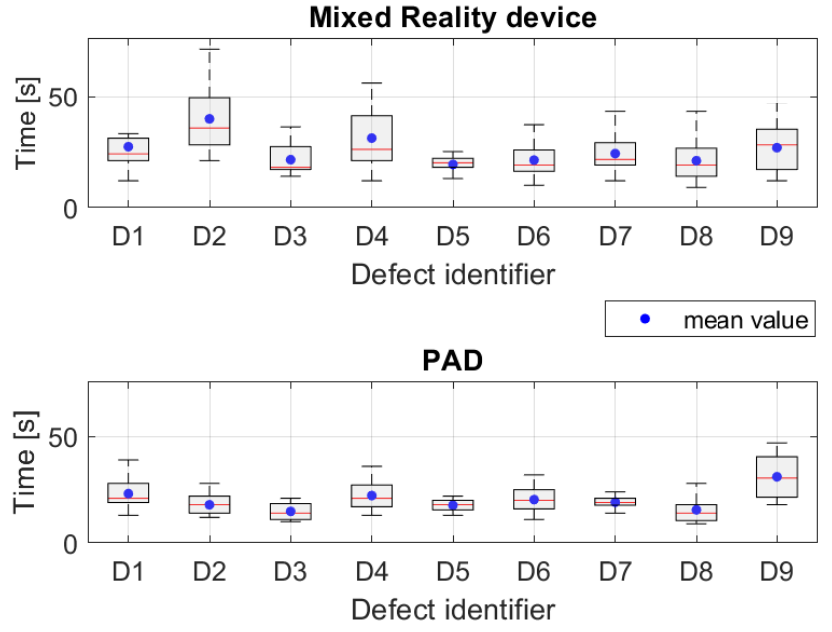

(b) Time employed per defect.

Fig. 16. Test A results: defect location, classification and performing time (the data sample size is equal to 41 users, 21 for the MR device and 20 for the PAD device); x-axis labels from D1 to D9 correspond to the defects shown in Table 3. 
that, in general, is grater in the case of the methodology based on MR than in the methodology based on PAD. Notwithstanding these issues, in general, the users have had greater success locating and marking the defects on the hood surface using the proposed MR-based user interface rather than using the PAD-based interface. This is an important result because it is a sign that the user makes fewer errors locating the defects, which implies that the user will also lose less time once he gets familiar with the methodology and has got enough practice.

Fig. 17 shows the results for Test B. A video demonstrative of the test using the PAD can be played following this link [58] and using the MR device with this link [59]. A total of 41 users performed this test: 20 for the MR device and 21 for the PAD device. The results of this test shows two interesting aspects of the proposed MR method. Firstly, the accuracy of the user indicating to the system the location of a new defect is much greater than in the case of conventional devices such as the PAD, see Fig. 17 (a). It is interesting to remark that this accuracy locating the defects has been obtained equally for users with previous experience in MR devices and for first-time users. Despite that, according to [57], the HoloLens first-time users usually focus more on the virtual objects than on the task objective, what may degrade their performance, which is not the case of this usability study. Secondly, the time required to introduce the location of new defects is equal to or less than in the case of conventional devices such as PADs, see Fig. 17(b). The latter is due to the fact that with the PAD the user doubts much more about whether the location she/he is introducing is correct or not, especially when there are few references such as edges, style lines, handles, etc.

Several questions were asked to the users at the end of each test in order to measure the following aspects of both methods: intuitiveness, comfort, user-friendliness and training adequacy. Fig. 18 shows the results obtained for this questionnaire. In the case of Test A (see Fig. 18(a)), the $95.00 \%$ of PAD users agreed with the training received, both in form and time, whilst the $85.66 \%$ in the case of the MR device users. On the other hand, the $80.00 \%$ of PAD users agreed that the application was easy to use, whilst the $85.80 \%$ in the case of the MR device users. In relation to the comfort, the $75.00 \%$ of the PAD users agreed that the use of this device was comfortable, whilst the $90.42 \%$ in the case of the MR device users. Finally, $85.00 \%$ of PAD users indicated that both the application and the device were intuitive, whilst $90.42 \%$ indicated it in the case of the MR application and device users. 

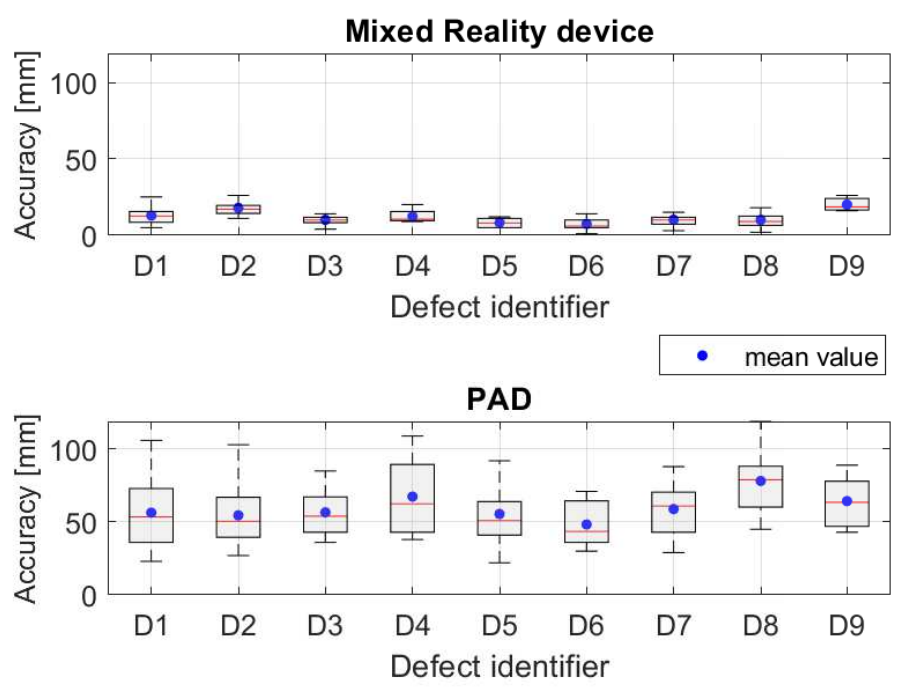

(a) Accuracy introducing the location of a new defect (perfect accuracy corresponds to $0 \mathrm{~mm}$ ).
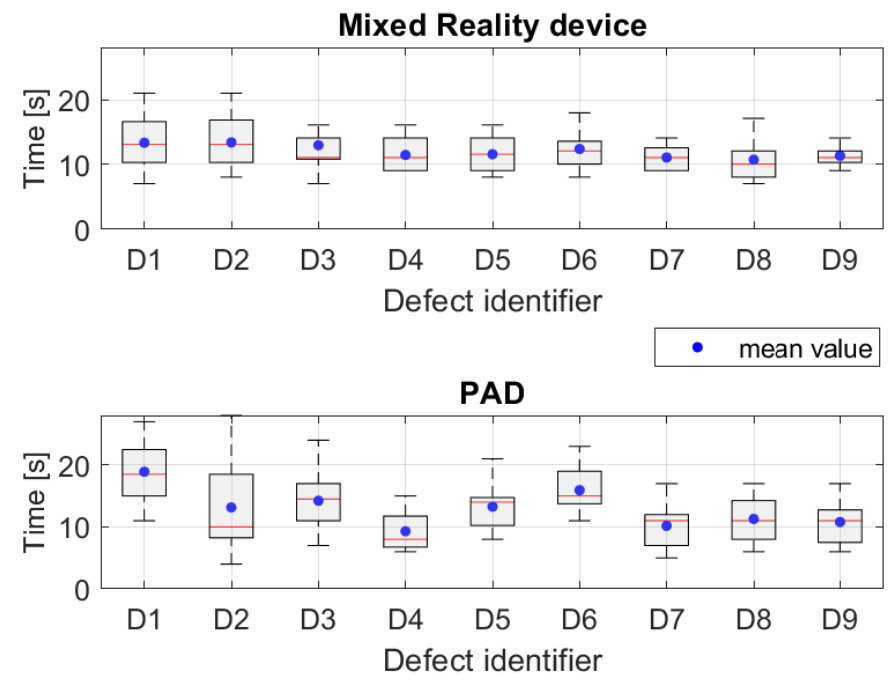

(b) Time employed per defect.

Fig. 17. Test B results: accuracy introducing the location of a new defect and performing time (the data sample size is equal to 41 users, 20 for the MR device and 21 for the PAD device); x-axis labels from D1 to D9 correspond to the defects shown in Table 3. 
In the case of Test B (see Fig. 18(b)), the $100.00 \%$ of both PAD and MR device users agreed with the training received, both in form and time. The $76.19 \%$ of PAD users agreed with that the application was easy to use, whilst the $80.00 \%$ in the case of the MR device users. In relation to the comfort, the $76.17 \%$ of the PAD users agreed that the use of this device was comfortable, whilst the $80.00 \%$ in the case of the MR device users. Finally, $66.70 \%$ of PAD users indicated that both the application and the device were intuitive, whilst $90.00 \%$ indicated it in the case of the MR application and device users.

Lastly, several questions were asked to the 41 users in order to know their opinion about the use of both methodologies in an industrial environment with a working day of 8 hours. Fig. 19 shows the results of this questionnaire: only the $31.71 \%$ of the PAD users have expressed their satisfaction with the accuracy, in front of the $78.05 \%$ of the MR device users; only the $26.83 \%$ of the PAD users have expressed their satisfaction with the comfort, in front of the $60.98 \%$ of the MR device users; the $68.29 \%$ of the PAD users have expressed their satisfaction with the manageability of the device, in front of the $80.49 \%$ of the MR device users; in relation of the ease of use of the application, both methodologies had similar opinions, being the satisfaction in $85.37 \%$ in the case of PAD and $87.80 \%$ in the case of MR device; finally, in both cases the $58.54 \%$ of the users have expressed their satisfaction with the device weight. Note that future MR devices will tend to reduce their weight, improving thus its current ergonomics.

\section{Discussion}

The results obtained in the usability study above show, in general, a relevant improvement in the performance of the tasks carried out for quality control of car surfaces. Despite many users had no previous experience in quality control tasks or MR devices, the results of Fig. 19 show a clear preference of the users towards the proposed MR-based interface over the conventional PAD-based interface. In particular, comfort and accuracy are the two indicators that have improved the most compared to the conventional PAD-based interface. Also note that the user satisfaction with the weight of both devices is very similar. Therefore, since comfort and manageability have clearly improved and weight satisfaction is similar, it can be concluded that the proposed MR-based interface has improved the worker's ergonomics compared to the PAD-based interface. 


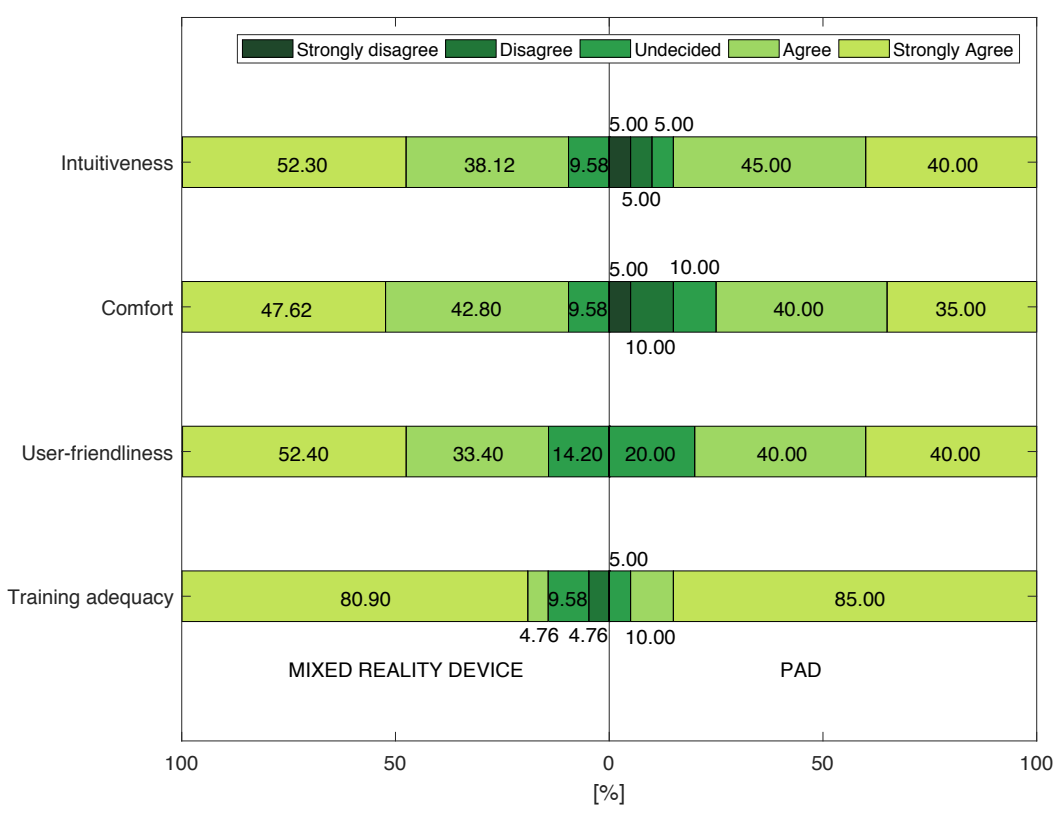

(a) Test A.

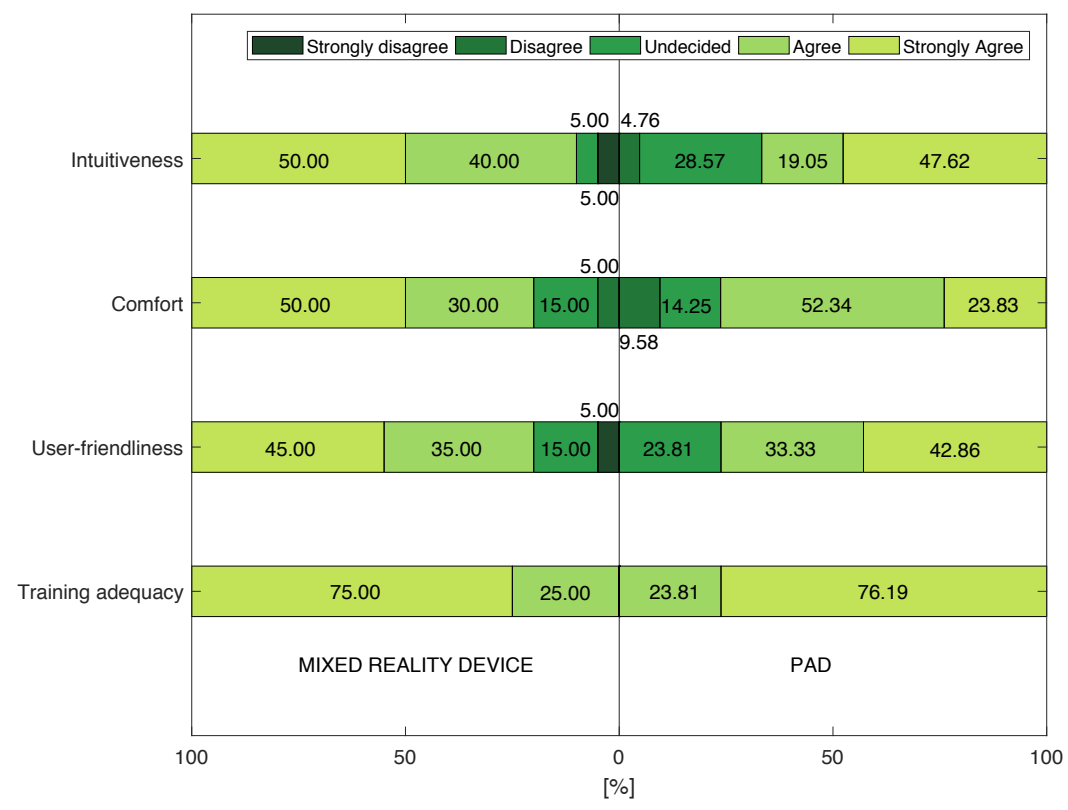

(b) Test B.

Fig. 18. User opinions regarding the intuitiveness, comfort, user-friendliness and training adequacy of the applications and devices used in each of the tests (the data sample size is equal to 41 users, of whom 21 performed both Test A with the MR device and Test B with the PAD device, and 20 performed both Test $\mathrm{B}$ with the MR device and Test A with the PAD device). 


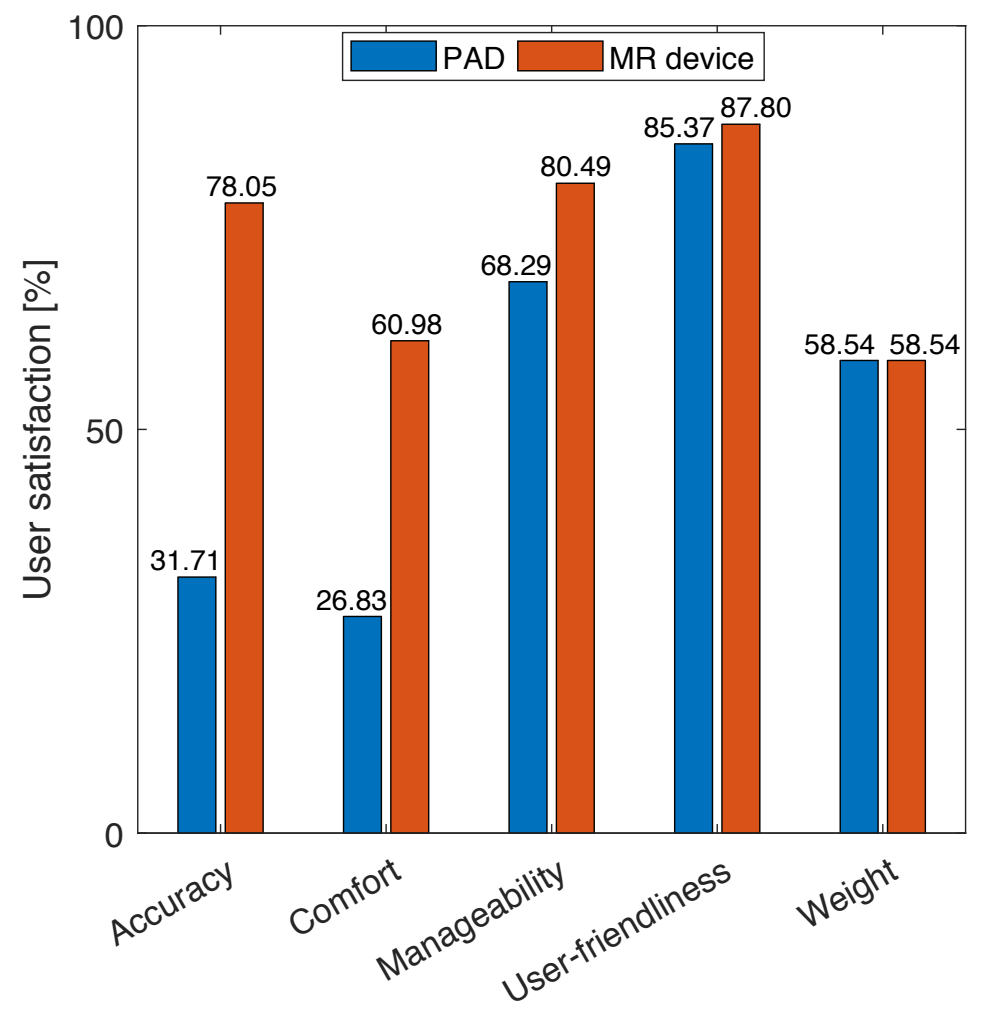

Fig. 19. User opinions regarding the accuracy, comfort, manageability, user-friendliness and weight of current PAD-based and proposed MR-based methodologies for being used in an industrial environment with a working day of 8 hours (the data sample size is equal to 41 users).

Moreover, the users have highly valued the ease of interaction with the proposed MR-based interface, which is slightly higher than the one for the PAD-based interfaces, although the vast majority of users were accustomed to PAD-based interfaces and very few of them were accustomed to MR-based interfaces.

Apart from that, the feedback obtained from the tests carried out with expert workers in factories, such as Mercedes-Benz or Volkswagen, has also been very positive. Many of the workers have highlighted the ease of interaction with the proposed MR-based interface, and the speed with which they can inspect the defects indicated by the automatic defect detection system. The expert workers also highlighted positively the short time in which a novice worker can join and perform inspection tasks by using the proposed 
MR-based interface ${ }^{4}$.

Although MR devices such as Microsoft ${ }^{\circledR}$ HoloLens glasses allow users to wear glasses, it has been detected some discomfort in users wearing glasses during common operations that require a close up, such as the observation of the surface of the car body in a regular quality control task.

Finally, it should be noted that the manufacturers of MR devices are currently developing new devices according to industrial demands and needs. For example, Microsoft will launch its new HoloLens 2 device at the end of year 2019 (see the following link [60] for more information). This device incorporates new features that will make the MR much more intuitive for the user, in addition to being more ergonomic. However, the interface proposed in this work is completely compatible with this type of devices and, in any case, easily transferable.

\section{Conclusions}

In this work a mixed reality-based user interface for quality control inspection of car body surfaces has been proposed in order to improve both ergonomics and productivity of workers.

A detailed description of the mockup methodology followed in order to develop the interface was presented. Moreover, the two main modules of the proposed mixed reality-based user interface, i.e., the zero-reference and inspection modules, were fully described.

The feasibility and robustness of the proposed mixed reality-based user interface were proved through real implementation in an industrial prototype.

In addition, usability tests were carried out with users, with and without experience, to demonstrate the advantages and drawbacks of the proposed mixed reality-based user interface compared with current PAD based user interfaces utilized in factories such as Mercedes-Benz. In particular, the results shown that the proposed mixed reality-based interface improved the user ergonomics in terms of comfort, and also improved the user productivity in terms of time and accuracy of the quality control tasks carried out.

\footnotetext{
${ }^{4}$ Novice workers must take courses taught by expert workers in quality control before being able to join the production line. These courses last several days and, subsequently, there is a process in which the novice worker is tutored until his/her supervisor gives the approval.
} 


\section{Acknowledgments}

This work was supported by the Spanish Government under the Project DPI2017-87656-C2-1-R.

\section{References}

[1] L. Armesto, J. Tornero, A. Herraez, J. Asensio, Inspection system based on artificial vision for paint defects detection on cars bodies, in: IEEE International Conference on Robotics and Automation, ICRA 2011, Shanghai, China, 9-13 May 2011, 2011, pp. 1-4. doi:10.1109/ICRA. 2011.5980570 .

[2] Micro-Epsilon, Micro-epsilon defect detection industrial solution, http://www.micro-epsilon.com/measurement-systems/ Paint-Inspection/karosserie/index.html (2015).

[3] L. Arnal, J. E. Solanes, J. Molina, J. Tornero, Detecting dings and dents on specular car body surfaces based on optical flow, Journal of Manufacturing Systems 45 (2017) 306-321. doi:10.1016/j.jmsy. 2017.07.006.

[4] J. Tornero, L. Armesto, M. C. Mora, N. Montés, A. Herráez, J. Asensio, Detección de defectos en carrocerías de vehículos basado en visión artificial: Diseño e implantación, Revista Iberoamericana de Automática e Informática Industrial RIAI 9 (1) (2012) 93-104. doi:10.1016/j. riai.2011.11.010.

[5] F. P. León, S. Kammel, Inspection of specular and painted surfaces with centralized fusion techniques, Measurement 39 (6) (2006) 536-546. doi:10.1016/j.measurement.2005.12.007.

[6] J. Santolaria, J. Velázquez, D. Samper, J. Aguilar, I. Escursell, Sistema de inspección de defectos opel españa, https://www.autobild.es/noticias/ opel-crea-sistema-que-encuentra-fallos-pintura-299855 (2016).

[7] ISRA, Paintscan: Paint inspection with in-line deflectometry, https: //www.isravision.com/en/ready-to-use/surface-inspection/ surface-coating-and-paint-inspection/paintscan/ (Accessed 08/19/2019). 
[8] AIS system, https://www. youtube.com/watch?v=HroEU8XsaTU (Accessed 08/19/2019).

[9] QEyeTunnel, https://www.youtube.com/watch?v=jN8vazudEXc (Accessed 08/19/2019).

[10] 3DJ Vision System, https ://youtu.be/LfwSpIBg_NE?t=115 (Accessed 08/19/2019).

[11] esPhi System, https://www.youtube.com/watch?v=QfwJmBN-tWY\& feature=youtu . be\&t=29 (Accessed 08/19/2019).

[12] AIS worker interface, https://www.youtube.com/watch?v= T1FE-c7s4cQ (Accessed 08/19/2019).

[13] 3DJ Vision worker interface, https://www.youtube.com/watch?v= LfwSpIBg_NE\&f eature=youtu . be\&t=115 (Accessed 08/19/2019).

[14] P. Milgram, H. Takemura, A. Utsumi, F. Kishino, Augmented reality: A class of displays on the reality-virtuality continuum, 1994, pp. 282292, http://citeseerx.ist.psu.edu/viewdoc/summary?doi=10.1. 1.83 .6861 .

[15] M. K. Bekele, R. Pierdicca, E. Frontoni, E. S. Malinverni, J. Gain, A survey of augmented, virtual, and mixed reality for cultural heritage, J. Comput. Cult. Herit. 11 (2) (2018) 7:1-7:36. doi:10.1145/3145534.

[16] G. Vignali, M. Bertolini, E. Bottani, L. D. Donato, A. Ferraro, F. Longo, Design and testing of an augmented reality solution to enhance operator safety in the food industry, International Journal of Food Engineering 14 (2017) 1 - 16. doi:10.1515/ijfe-2017-0122.

[17] R. Masoni, F. Ferrise, M. Bordegoni, M. Gattullo, A. E. Uva, M. Fiorentino, E. Carrabba, M. D. Donato, Supporting remote maintenance in industry 4.0 through augmented reality, Procedia Manufacturing 11 (2017) 1296 - 1302, 27th International Conference on Flexible Automation and Intelligent Manufacturing, FAIM2017, 27-30 June 2017, Modena, Italy. doi:10.1016/j.promfg.2017.07.257.

[18] A. E. Uva, M. Gattullo, V. M. Manghisi, D. Spagnulo, G. L. Cascella, M. Fiorentino, Evaluating the effectiveness of spatial augmented reality 
in smart manufacturing: a solution for manual working stations, The International Journal of Advanced Manufacturing Technology 94 (1) (2018) 509-521. doi:10.1007/s00170-017-0846-4.

[19] M. Gattullo, G. W. Scurati, M. Fiorentino, A. E. Uva, F. Ferrise, M. Bordegoni, Towards augmented reality manuals for industry 4.0: A methodology, Robotics and Computer-Integrated Manufacturing 56 (2019) 276 - 286. doi:10.1016/j.rcim.2018.10.001.

[20] R. Hanson, W. Falkenstrom, M. Miettinen, Augmented reality as a means of conveying picking information in kit preparation for mixedmodel assembly, Computers and Industrial Engineering 113 (2017) 570 - 575. doi:10.1016/j.cie.2017.09.048.

[21] C. Liu, S. Cao, W. Tse, X. Xu, Augmented reality-assisted intelligent window for cyber-physical machine tools, Journal of Manufacturing Systems 44 (2017) 280 - 286, special Issue on Latest advancements in manufacturing systems at NAMRC 45. doi:10.1016/j.jmsy.2017.04.008.

[22] J. P. Lima, R. Roberto, F. Simões, M. Almeida, L. Figueiredo, J. M. Teixeira, V. Teichrieb, Markerless tracking system for augmented reality in the automotive industry, Expert Systems with Applications 82 (2017) 100 - 114. doi:10.1016/j. eswa.2017.03.060.

[23] J. Neves, D. Serrario, J. N. Pires, Application of mixed reality in robot manipulator programming, Industrial Robot: the international journal of robotics research and application 45 (6) (2018) 784-793. doi:10. 1108/IR-06-2018-0120.

[24] E. Bottani, G. Vignali, Augmented reality technology in the manufacturing industry: a review of the last decade, IISE Transactions 0 (ja) (2018) 1-64. doi:10.1080/24725854.2018.1493244.

[25] C. Liu, H. Vengayil, Y. Lu, X. Xu, A cyber-physical machine tools platform using opc ua and mtconnect, Journal of Manufacturing Systems 51 (2019) 61 - 74. doi:https://doi.org/10.1016/j.jmsy.2019.04. 006.

[26] V. J. Mawson, B. R. Hughes, The development of modelling tools to improve energy efficiency in manufacturing processes and systems, 
Journal of Manufacturing Systems 51 (2019) 95 - 105. doi:https: //doi.org/10.1016/j.jmsy.2019.04.008.

[27] B. Denkena, H. Ahlers, F. Berg, T. Wolf, H. Tonshoff, Fast inspection of larger sized curved surfaces by stripe projection, CIRP Annals - Manufacturing Technology 51 (1) (2002) 499 - 502. doi:10.1016/ S0007-8506 (07) 61570-4.

[28] A. Yogeswaran, P. Payeur, Features extraction from point clouds for automated detection of deformations on automotive body parts, in: 2009 IEEE International Workshop on Robotic and Sensors Environments, 2009, pp. 122-127. doi:10.1109/ROSE.2009.5355976.

[29] V. Borsu, A. Yogeswaran, P. Payeur, Automated surface deformations detection and marking on automotive body panels, in: 2010 IEEE International Conference on Automation Science and Engineering, 2010, pp. 551-556. doi:10.1109/COASE. 2010.5584643.

[30] Z. Sárosi, W. Knapp, A. Kunz, K. Wegener, Detection of surface defects on sheet metal parts by using one-shot deflectometry in the infrared range, ETH Zurich, IWF, 2010, https://books.google.com. au/books? id=8-w6AwEACAAJ.

[31] S. Werling, M. Mai, M. Heizmann, J. Beyerer, Inspection of specular and partially specular surfaces, Metrology and Measurement Systems 16 (3) (2009) 415-431, http://publica.fraunhofer.de/documents/ $\mathrm{N}-113371 . h t m l$.

[32] S. Hofer, J. Burke, M. Heizmann, Infrared deflectometry for the inspection of diffusely specular surfaces, Advanced Optical Technologies 5 (2016) 377 - 387. doi:10.1515/aot-2016-0051.

[33] J. Molina, J. E. Solanes, L. Arnal, J. Tornero, On the detection of defects on specular car body surfaces, Robotics and Computer-Integrated Manufacturing 48 (2017) 263 - 278. doi:http://dx.doi.org/10.1016/j. rcim.2017.04.009.

[34] R. Hess, Blender Foundations: The Essential Guide to Learning Blender 2.6, Focal Press, 2010, https://www.sciencedirect.com/ book/9780240814308/blender-foundations. 
[35] S. Jackson, Unity 3D UI Essentials, Packt Publishing, 2015, https: //dl.acm.org/citation. cfm?id=2789365.

[36] Moqups Software, https://moqups.com/ (Accessed 08/19/2019).

[37] Chapter 2 - geometric analysis, in: J. S. Aber, A. Ber (Eds.), Glaciotectonism, Vol. 6 of Developments in Quaternary Sciences, Elsevier, 2007, pp. 17 - 32. doi:https://doi.org/10.1016/S1571-0866(07) 80070-4.

[38] H. Durrant-Whyte, T. Bailey, Simultaneous localization and mapping: part i, IEEE Robotics Automation Magazine 13 (2) (2006) 99-110. doi: 10.1109/MRA. 2006.1638022.

[39] T. Bailey, H. Durrant-Whyte, Simultaneous localization and mapping (slam): part ii, IEEE Robotics Automation Magazine 13 (3) (2006) 108-117. doi:10.1109/MRA.2006.1678144.

[40] Microsoft Spatial mapping demo, https://docs.microsoft. com/en-us/windows/mixed-reality/spatial-mapping (Accessed 08/19/2019).

[41] M. B. Selleck, D. Burke, C. Johnston, V. Nambiar, Augmented reality integration of fused lidar and spatial mapping, Vol. 10666, 2018, pp. 10666 - 10666 - 9. doi:10.1117/12.2304977.

[42] J. Ojeda-Castañeda, Foucault, Wire, and Phase Modulation Tests, John Wiley \& Sons, Ltd, 2006, Ch. 8, pp. 275-316. doi:10.1002/ 9780470135976.ch8.

[43] Microsoft Hololens, Hololens (1st gen) hardware details, https://docs.microsoft. com/en-us/windows/mixed-reality/ hololens-hardware-details (Accessed 08/19/2019).

[44] A. Coppens, Merging real and virtual worlds: An analysis of the state of the art and practical evaluation of microsoft hololens, CoRR abs/1706.08096. arXiv:1706.08096.

[45] D. Y. Park, Mrtk: Open-source building blocks for windows mixed reality experiences, https://github.com/cre8ivepark/ (2017). 
[46] T. V. E. Team, Vuforia engine developer portal, https://developer. vuforia.com/ (2019).

[47] Mixed reality-based user interface: demo1, https://media.upv. es/player/?id=83fe29a0-2869-11e9-8fef-e30aa8ecd453 (Accessed 08/19/2019).

[48] Mixed reality-based user interface: demo2, https://media.upv. es/player/?id=ba4fa650-2869-11e9-8fef-e30aa8ecd453 (Accessed 08/19/2019).

[49] Mixed reality-based user interface: demo3, https://media.upv. es/player/?id=f89e93d0-2869-11e9-8fef-e30aa8ecd453 (Accessed 08/19/2019).

[50] Mixed reality-based user interface: demo4, https://media.upv. es/player/?id=464e93f0-286a-11e9-8fef-e30aa8ecd453 (Accessed 08/19/2019).

[51] J. Blattgerste, B. Strenge, P. Renner, T. Pfeiffer, K. Essig, Comparing Conventional and Augmented Reality Instructions for Manual Assembly Tasks, in: Proceedings of the 10th International Conference on PErvasive Technologies Related to Assistive Environments, ACM, 2017, pp. 75 - 82. doi:10.1145/3056540.3056547.

[52] C.-H. Wang, N.-H. Tsai, J.-M. Lu, M.-J. J. Wang, Usability evaluation of an instructional application based on google glass for mobile phone disassembly tasks, Applied Ergonomics 77 (2019) 58 - 69. doi:10.1016/ j.apergo.2019.01.007.

[53] K. Helin, T. Kuula, C. Vizzi, J. Karjalainen, A. Vovk, User experience of augmented reality system for astronaut's manual work support, Frontiers in Robotics and AI 5 (2018) 106. doi:10.3389/frobt. 2018. 00106.

[54] J. Brooke, "SUS-A quick and dirty usability scale." Usability evaluation in industry, CRC Press, 1996, iSBN: 9780748404605 https: //www. crcpress. com/product/isbn/9780748404605. 
[55] Mixed reality-based user interface: demo5, https://media.upv. es/player/?id=056baa90-2869-11e9-8fef-e30aa8ecd453 (Accessed 08/19/2019).

[56] Mixed reality-based user interface: demo6, https://media.upv. es/player/?id=e44fb6d0-2868-11e9-8fef-e30aa8ecd453 (Accessed 08/19/2019).

[57] M. W. Hoover, An evaluation of the microsoft hololens for a manufacturing-guided assembly task, in: Graduate theses and dissertations, Iowa State University, USA, 2018, p. 60. doi:10.31274/ etd-180810-6008.

[58] Mixed reality-based user interface: demo7, https://media.upv. es/player/?id=35a20b00-2869-11e9-8fef-e30aa8ecd453 (Accessed 08/19/2019).

[59] Mixed reality-based user interface: demo8, https://media.upv. es/player/?id=1dcbe690-2869-11e9-8fef-e30aa8ecd453 (Accessed 08/19/2019).

[60] Microsoft Hololens (1st gen) hardware details, https://www . microsoft. com/en-us/hololens/hardware (Accessed 08/19/2019). 